NASA Technical Memorandum 105695

AIAA 92-3088

\title{
A Parametric Numerical Study of Mixing in a Cylindrical Duct
}

V.L. Oechsle and H.C. Mongia

Allison Gas Turbine Division

General Motors Corporation

Indianapolis, Indiana

and

J.D. Holdeman

National Aeronautics and Space Administration

Lewis Research Center

Cleveland, Ohio

Prepared for the

28th Joint Propulsion Conference and Exhibit

cosponsored by the AIAA, SAE, ASME, and ASEE

Nashville, Tennessee, July 6-8, 1992 


\author{
V. L. Oechsle and H. C. Mongia* \\ Allison Gas Turbine Division \\ General Motors Corporation \\ Indianapolis, IN 46206 \\ J. D. Holdeman ${ }^{\dagger}$ \\ National Aeronautics and Space Administration \\ Lewis Research Center \\ Cleveland, $\mathrm{OH} 44135$
}

\section{$\underline{\text { Abstract }}$}

This paper describes the interaction of some of the important parameters affecting the mixing process in a quick mixing region of a rich burn/quick mix/lean burn (RQL) combustor. The performance of the quick mixing region is significantly affected by the geometric designs of both the mixing domain and the jet inlet orifices. In this paper, several of the important geometric parameters and operating conditions affecting the mixing process were analytically studied. Parameters such as jet-to-mainstream momentum flux ratio (J), mass flow ratio (MR), orifice geometry, orifice orientation, and number of orifices/row (equally spaced) around the circumferential direction have been analyzed. Three different sets of orifice shapes were investigated: (1) square, (2) elongated slots, and (3) equilateral triangles. Based on the analytical results, the best mixing configuration depends significantly on the penetration depth of the jet to prevent the hot mainstream flow from being entrained behind the orifice. The structure in a circular mixing section is highly weighted toward the outer wall and any mixing structure affecting this area significantly affects the overall results. The increase in the number of orifices per row increases the mixing performance. Strong swirl in the quick mixing region appears to have an adverse effect on mixing at higher J conditions. Higher slot slant angles and aspect ratios are generally the best mixing configurations at higher momentum-flux ratio (J) conditions. However, the square and triangular shaped orifices were more effective mixing configurations at lower J conditions.

\section{Nomenclature}

\section{Variables}

$$
\begin{aligned}
& \text { AMIX }=\text { overall enthalpy variance from } h_{\text {eq }}, \mathrm{Eq} 4 \\
& \mathrm{AHOT}=\text { enthalpy variance above } h_{\text {eq }}, \mathrm{Eq} 5 \\
& \mathrm{ACOLD}=\text { enthalpy variance below heq, } \mathrm{Eq} 6 \\
& \mathrm{~B}=\text { area determined half-width of the } \\
& \text { distribution function, Figure } 2 \\
& \text { C = arithmetic average of the distribution } \\
& \text { function, Figure } 2 \\
& \mathrm{DF}=\text { distribution function (histogram), Figure } 2 \\
& \mathrm{DR} \quad=\text { density ratio (jet/mainstream) } \\
& \mathrm{DP} / \mathrm{P} \quad=\text { pressure drop across the mixing wall } \\
& \mathrm{f}=\text { nondimensional specific enthalpy, Eq } 2 \\
& \mathrm{~h}=\text { specific enthalpy } \\
& \mathrm{J}=\text { momentum flux ratio (jet/mainstream) }=\mathrm{M}^{2} / \mathrm{DR} \\
& \mathrm{L} \quad=\text { slot length (long dimension) } \\
& \text { m }=\text { mass flowrate } \\
& \mathrm{M} \quad=\text { mass flux ratio (jet } / \text { mainstream) }=\mathrm{DR} \mathrm{V}_{\text {jet }} / \mathrm{U}_{\text {main }} \\
& \text { MR }=\text { mass flowrate ratio (jet/mainstream) } \\
& \mathrm{R}=\quad \text { radius of the mixing section } \\
& \mathrm{S}=\text { spacing between orifice centers } \\
& \mathrm{T}=\text { temperature }-\mathrm{K} \\
& \mathrm{U}_{\text {main }} \quad=\text { inlet mainstream axial velocity } \\
& V_{\text {jet }} \quad=\text { radial velocity of the jet } \\
& \mathrm{VR} \quad=\text { velocity ratio (jet } / \text { mainstream })=V_{\text {jet }} / U_{\text {main }} \\
& \mathrm{W} \quad=\text { slot width (short dimension) } \\
& X=\text { axial distance from the leading edge of the }
\end{aligned}
$$

\section{-AlaA member}

tSenior Research Engineer, Senior Member AIAA

Copyright $\odot 1992$ by the American Institute of Aeronautics and Astronautics, Inc. No copyright is asserted in the United States under Title 17, U.S. Code. The U.S. Government has a royalty-free license to exercise all rights under the copyright claimed herein for Governmental purposes. All other rights are reserved by the copyright owner.

\section{Introduction}

A number of advanced technologies are being developed for incorporation in the future generation turbopropulsion engines to simultaneously achieve challenging goals of improved efficiency, reduced life-cycle cost, lower noise, and exhaust gaseous and particulate emissions. The major exhaust species of concern are unburned hydrocarbons (UHC), carbon monoxide (CO), smoke, and oxides of nitrogen $\left(\mathrm{NO}_{\mathrm{x}}\right)$. The UHC, $\mathrm{CO}$, and smoke emissions from modern gas turbines have been reduced significantly by making design improvements (e.g., good fuel spray atomization quality and minimum quenching during low power operation) with little impact on life-cycle cost and safety. Although some progress has been made in lowering the $\mathrm{NO}_{x}$ emissions by reducing the combustor length and the areas of stoichiometric combustion, the limitations of conventional single-stage turbopropulsion combustors are well known in regard to how much $\mathrm{NO}_{x}$ emissions can be reduced without impacting operational safety.

A promising approach to achieve significant $\mathrm{NO}_{x}$ reductions for future-generation engines with very high cycle pressure ratios and turbine inlet temperatures is staged combustion (Rizk and Mongia, 1990, 1991). The first stage is a rich burn zone in which fuel reacts at temperatures significantly below the stoichiometric temperature to prevent the formation of $\mathrm{NO}_{\mathrm{x}}$. Typical rich burn zones operate at equivalence ratios between 1.3 to 1.8 and reaction temperatures of about $1800 \mathrm{~K}$. The second zone is a quick mixing region in which the hot gases exiting the rich burn region are rapidly mixed with additional air to minimize formation of $\mathrm{NO}_{\mathrm{x}}$. The third zone is a lean burn zone typically operating at an equivalence ratio of about 0.7 to 0.5 . In this zone, the combustion process is completed by oxidizing the partially burned combustion products of the rich zone.

As discussed by Rizk and Mongia (1990, 1991), RQL NO emissions can be reduced by improving the mixing in the rich zone; increasing the rich zone length and residence time; using an optimum rich zone equivalence ratio; and achieving the quickest possible rate of mixing in the quench zone. The latter has been shown to be the most critical process for controlling $\mathrm{NO}_{x}$ emissions from $\mathrm{RQL}$ combustors (Rizk and Mongia, 1991). For example, $\mathrm{NO}_{\mathrm{x}}$ produced in the quench zone can be as high as $90 \%$ of the total $\mathrm{NO}_{\mathrm{x}}$ emissions of a current technology RQL combustor.

To understand the fundamental processes within the mixing zone, a systematic detailed experimental and analytic effort is being conducted by several investigators (Hatch, Sowa, Samuelsen, Holdeman, 1992; Talpallikar, Smith, Lai, Holdeman, 1991; Vranos, Liscinsky, True, Holdeman, 1991; and Smith, Talpallikar, Holdeman, 1991). Multidimensional gas turbine combustor models (e.g., COM3D) can be used to analytically screen the effects of important design variables (e.g., $\Delta \mathrm{P}, \mathrm{MR}$, rich zone equivalence ratio, J), geometric variables including shape, orientation, and number of air injection orifices on the quench zone mixing processes, and attendant $\mathrm{NO}_{x}$ formation. This paper summarizes recent work in modeling nonreacting flow fields in a simple mixing zone test section for which experimental data have recently been reported by Hatch et al., 1992. Parameters such as orifice geometry, orifice orientation, and number of orifices (equally spaced) around the circumferential direction were analyzed. Results are presented describing the relation of several parameters. This study also describes the interaction of multiple jets and how this affects the mixing process in a cylindrical duct. Acceptable agreement has been found between the qualitative and quantitative results using several statistical 
correlations to examine the numerical results to evaluate the mixing performance of a given configuration.

\section{Mathematical Model}

A production 3-D combustor code (COM-3D) solves the turbulent reacting flow transport equations using the SIMPLE algorithm of Patankar and Spalding (Patankar, 1980). This program simulates turbulence by the two-equation $k-\varepsilon$ model (Launder and Spalding, 1974) and combustion following vaporization is determined by a four-step chemical reaction model based on Arrhenius and eddy breakup concepts (Mongia and Reynolds, 1979). The transport equations for all dependent variables are of the following form as shown in Eq 1:

$$
\operatorname{div}\left[\rho \mathrm{u} \xi-\left(\mu_{\mathrm{eff}} / \mathrm{P}_{\mathrm{r}}\right) \operatorname{grad}(\xi)\right]=\mathrm{S}_{\xi}
$$

where $\rho$ is the mixture density, $u$ is the velocity, $\mu_{\text {eff }}$ is the effective turbulent viscosity, $\mathrm{P}_{\mathrm{r}}$ is the effective Prandtl/Schmidt number, and $\mathrm{S}_{\xi}$ is the source term for the variable $\gamma$. The following variables are computed by the three-dimensional code: (1) axial, radial, and swirl velocity components; (2) specific enthalpy and temperature; (3) turbulence kinetic energy and dissipation rate; (4) unburned fuel and composite fuel fraction; and (5) fuel spray trajectory and evaporation rate.

The computational effort is significantly reduced by modeling a sector of the mixing section comprising a single orifice. Therefore, the shape of the sector was dependent on the number of orifices equally spaced in the circumferential direction. Periodic boundary conditions were applied in the circumferential direction. These conditions were necessary for the mixing configurations generating swirl during the mixing process generally characteristic of the slanted slot orifice configurations. No-slip and adiabatic boundary conditions were applied at the outer wall defining the inside wall of the quick mixing section tube. The computation at the center axis was extrapolated based on the nearest surrounding values due to its singularity. No-gradient and slip boundary conditions were applied at the center axis. Fully developed profiles (no axial gradients) were assumed at the exit boundary condition.

\section{Geometric Configuration}

In this study, the quick mixing section was modeled as a constant diameter cylindrical "can" with a single row of equally spaced orifices. The outer wall diameter is $80 \mathrm{~mm}$ and the axial length of the mixing section extended from $X / R=-1$ to $X / R=5$ where $X$ is referenced from the leading edge of the orifice. Sufficient axial distance was provided both upstream and downstream of the orifice to prevent any entry or exit effects from modifying the flow structure in the computational domain of interest which is $X / R<2$. The computational grid of the domain typically consists of 20,000 to 30,000 control volumes. The grid was typically denser near the orifice to resolve the high velocity and temperature gradients resulting from the inlet of the crossflow jet. An orthogonal view of the computational grid is shown in Figure 1. The grid was also configured to allow smooth progressive volume change between adjacent control volumes to help speed up the convergence of the solution.

The geometric configurations of the jet orifices are also shown in Figure 1. Three different general shapes of orifices were modeled: square, slanted slots, and equilateral triangles, and a total of 21 different configurations were analyzed. Multiple shapes, number, and orientations were analyzed and the different orifice configurations
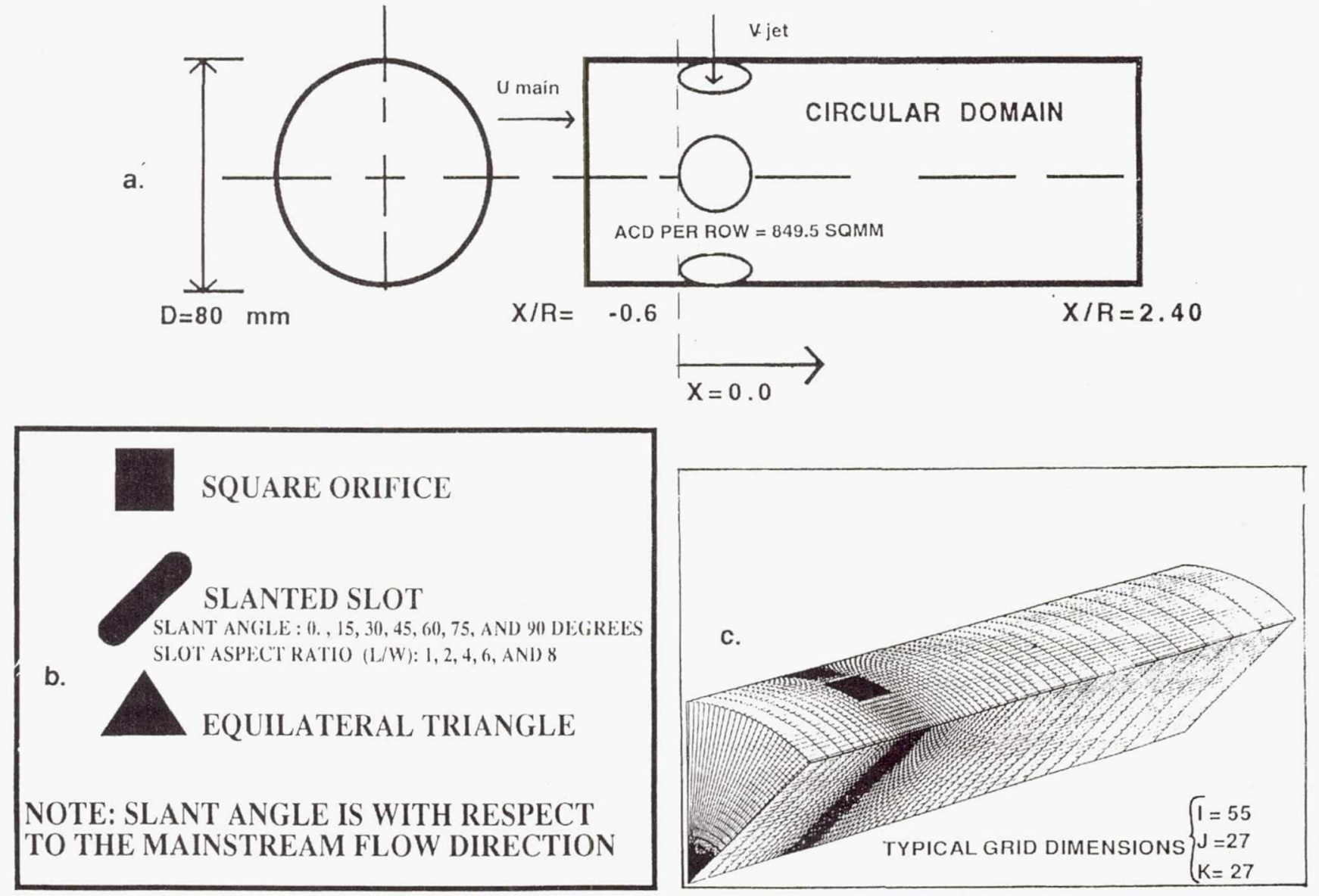

Figure 1. Depiction of (a) geometric configuration of the mixing section; (b) orifice description; and

(c) computational grid. 
Table 1.

Configuration description.

\begin{tabular}{|c|c|c|c|c|c|c|}
\hline $\begin{array}{c}\text { CONF } \\
\#\end{array}$ & $\begin{array}{c}\text { ORIFICE } \\
\text { TYPE }\end{array}$ & $\begin{array}{c}\text { SLANT } \\
\text { ANGLE }\end{array}$ & L/W & $\begin{array}{c}\text { \# ORIFICES } \\
\text { PER ROW }\end{array}$ & & $\begin{array}{c}\text { ORIFICE } \\
\text { T.E.* } \text { X/R }\end{array}$ \\
\hline 1 & SQUARE & & & 6 & 0.319 & 0.338 \\
\hline 2 & SQUARE & & & 8 & 0.382 & 0.309 \\
\hline 3 & SQUARE & & & 10 & 0.405 & 0.263 \\
\hline 4 & SQUARE & & & 12 & 0.454 & 0.245 \\
\hline 5 & SQUARE & & & 16 & 0.520 & 0.204 \\
\hline 6 & SLOT & 45 DEG & 1 & 8 & 0.525 & 0.418 \\
\hline 7 & SLOT & 45 DEG & 2 & 8 & 0.432 & 0.383 \\
\hline 8 & SLOT & 0 DEG & 4 & 8 & 0.189 & 0.619 \\
\hline 9 & SLOT & 15 DEG & 4 & 8 & 0.300 & 0.591 \\
\hline 10 & SLOT & 30 DEG & 4 & 8 & 0.521 & 0.531 \\
\hline 11 & SLOT & 45 DEG & 4 & 8 & 0.565 & 0.440 \\
\hline 12 & SLOT & 45 DEG & 6 & 8 & 0.684 & 0.550 \\
\hline 13 & SLOT & 45 DEG & 8 & 8 & 0.750 & 0.602 \\
\hline 14 & SLOT & 60 DEG & 4 & 8 & 0.671 & 0.377 \\
\hline 15 & SLOT & 75 DEG & 4 & 8 & 0.735 & 0.275 \\
\hline 16 & SLOT & 90 DEG & 4 & 8 & 0.765 & 0.155 \\
\hline 17 & 2-D SLOT & 90 DEG & 7 & 8 & 1.000 & 0.106 \\
\hline 18 & TRIANGLE & BASE DWNSTR & & 8 & 0.498 & 0.318 \\
\hline 19 & TRIANGLE & BASE UPSTR & & 6 & 0.443 & 0.451 \\
\hline 20 & TRIANGLE & BASE UPSTR & & 8 & 0.478 & 0.387 \\
\hline 21 & TRIANGLE & BASE UPSTR & & 12 & 0.633 & 0.317 \\
\hline
\end{tabular}

NOTE: The effective area of the orifice divided by the area of the mixing section is 0.169 for all configurations in Table-1.

* T.E. is the trailing edge of the orifice

are shown in Table 1. The effective orifice area (ACd) of the entire orifice row and orifice coefficient of discharge was maintained constant ( $849.5 \mathrm{~mm}^{2}$ and 0.8 , respectively) throughout the entire parametric study. This also indicates that the area ratio between the orifice and the mixing section (orifice area/can area $=0.169$ ) is also constant for all configurations described in Table 1. The model of the orifice perimeter was accomplished by a stair-stepping approximation since COM-3D is not a body-conforming code. For example, the orifice models of configurations 18 and 20 (Table 1) are slightly different due to computational grid density. Therefore, to increase the modeling accuracy, the orifice was typically defined with 30 to 100 control volumes.

The mixing section was modeled at atmospheric pressure. The mainstream flow and jet flow conditions are shown in Table 2 . The mainstream temperature, mainstream flowrate, and jet temperature were maintained constant throughout the parametric study. The variation in J was chosen as a representative range for typical gas turbine combustion systems. The mainstream flow at the inlet of the modeled mixing region was characterized by a uniform temperature and axial plug flow velocity profiles in the radial and circumferential plane. The air jet flow was characterized by a radial, uniform flow across the orifice effective area. The turbulence kinetic energy of the mainstream and jet flows were $0.3 \%$ of the mean velocities. The turbulent length scales of the mainstream flow were $2 \%$ of the can diameter, and the turbulent length scale of the jet was of the order or the orifice diameter. The inlet conditions for all orifices in the mixing section were equal to create a symmetrical input condition about the circumferential direction that was necessary for the sector analysis. The operating pressure and temperature range was chosen to simplify the experimental setup for future numerical validation.
A typical numerical solution took about 250 iterations for full convergence with overall mass flow residuals of $0.05 \%$ of the total mixing section mass flowrate. All solutions were obtained using the Cray Y-MP and a typical converged solution took about $1 / 2 \mathrm{hr}$ of CPU time.

\section{$\underline{\text { Results and Discussions }}$}

The mixing performance for all configurations analyzed in this study were evaluated at $X / R=1$. Two different methods were used to analyze the numerical results:

1. The results were analyzed qualitatively by visual observation of the enthalpy and velocity field solutions. The specific enthalpy plots presented in this paper describe a domain from $X / R=-0.6$ to $X / R=2.4$. In all axial-radial enthalpy plots, the air flows from left to right and the air flows into the paper for the radial-tangential plots. The bottom boundary on all axial-radial plots constitutes the center axis of the mixing section and the upper boundary is the outer wall. The representative two-dimensional plane slices illustrated in this paper are:

a. axial-radial plane slices through the center of the orifice (The axial direction is plotted in the abscissa.)

b. radial-tangential plots at $X / R=1$ downstream from the orifice

The specific enthalpy results are presented as normalized values with respect to the overall heat differential between the mainstream flow and the jet flow. This normalized specific enthalpy is defined in Eq 2.

Table 2 .

Operating conditions of the mixing section.

\begin{tabular}{|c|c|c|c|c|c|c|c|c|c|c|}
\hline $\begin{array}{c}\text { CODE } \\
\text { PREFIX }\end{array}$ & $\begin{array}{c}\mathrm{T} \text { main } \\
\text { deg K }\end{array}$ & $\begin{array}{c}\text { V main } \\
\mathrm{m} / \mathrm{sec}\end{array}$ & $\begin{array}{c}\mathrm{T} \text { jet } \\
\text { deg K }\end{array}$ & $\begin{array}{c}\mathrm{V} \text { jet } \\
\mathrm{m} / \mathrm{sec}\end{array}$ & MR & DR & VR & J & $\begin{array}{c}\text { DP/P } \\
\%\end{array}$ & $\begin{array}{c}\text { Equil } \\
\text { enthalpy }\end{array}$ \\
\hline $\mathrm{A}$ & 588 & 10.8 & 300 & 39.1 & 0.96 & 1.57 & 3.61 & 20.55 & 0.708 & $\mathbf{0 . 5 1 0}$ \\
\hline $\mathrm{B}$ & 588 & 10.8 & 300 & 52.1 & 1.28 & 1.57 & 4.82 & 36.55 & 1.258 & $\mathbf{0 . 4 3 9}$ \\
\hline $\mathrm{C}$ & 588 & 10.8 & 300 & 78.1 & 1.92 & 1.57 & 7.23 & $\mathbf{8 2 . 1 8}$ & 2.831 & $\mathbf{0 . 3 4 3}$ \\
\hline
\end{tabular}




$$
f=\frac{h-h_{\text {jet }}}{h_{\text {main }}-h_{\text {jet }}}
$$

Note: This is a conserved scalar axially beyond the jet injection.

The value of $\mathrm{f}$ varies from 0 to 1 , where 0 is the value of the unmixed jet and 1 is the value of mainstream flow. Note that $f=$ $1-\theta$, where $\theta$ is as defined previously (Holdeman, 1991). The value of equilibrium specific enthalpy was calculated in an adiabatic system. The equilibrium enthalpy was also normaiized in the same manner as the specific enthalpy.

2. The numerical results were also quantitatively analyzed using two different statistical techniques.

a. The mixing effectiveness was defined quantitatively by subdividing the specific enthalpy field at the radial-tangential plane corresponding to $X / R=1$ into 20 bins covering the entire enthalpy range from lowest enthalpy (jet) to the highest (mainstream). The enthalpy of each computational grid control volume was calculated and sorted into its appropriate bin, and this procedure was done with all control volumes. The definition of the distribution function (DF) is of the form as described in Eq 3 and Figure 2.

$$
\text { DF histogram }=\frac{\sum_{h_{L}+\Delta h}^{h_{L}}\left(\dot{m}_{i j k} h_{i j k}\right)}{\sum_{h_{L}+\Delta h}^{h_{L}}\left(\dot{m}_{i j k}\right)}
$$

With this information, a mass flux weighted specific enthalpy distribution density function (DF) was constructed from the data. The partial enthalpy corresponding to each enthalpy bin was then normalized with respect to the enthalpy contained at the plane located at $X / R=1$. There- fore, ideal mixing would occur at a location downstream of the injection plane where the value of the corresponding distribution function is 1.0 at the appropriate enthalpy bin, which coincides with the equilibrium enthalpy (heq). Subsequently, the mixing effectiveness was quantified by the shape of the histogram (DF) formed by plotting the normalized enthalpy bin values (abscissa) and distribution function DF (ordinate). To further quantify the shape of the distribution function, the following parameters shown in Figure 2 were defined:

i. $\mathrm{B}(+)$ and $\mathrm{B}(-)$ are the "area determined" distribution half width. $B(+)$ is the half width above the equilibrium enthalpy, which is the deviation from heq such that the area under the histogram (DF) from $h_{\text {eq }}$ to $B(+)$ is $1 / 2$ that of the overall distribution area above $h_{e q}$. The same is applicable for $\mathrm{B}(-)$ with the area below heq. The definition of both $\mathrm{B}(+)$ and $\mathrm{B}(-)$ are shown pictoriaily in Figure 2.

ii. $C(+)$ and $C(-)$ are the distribution half width area average values. $\mathrm{C}(+)$ is the overall arithmetic average of the distribution function for the values above $h_{\text {eq. }}$. The same is applicable to $\mathrm{C}(-)$. The definition of both $\mathrm{C}(+)$ and $\mathrm{C}(-)$ are shown pictorially in Figure 2 . The area described by the rectangle with base of $2 \mathrm{~B}(+)$ and height of $\mathrm{C}(+)$ equals the area of the DF histogram above heq. Similarly, the rectangle described by base of $2 \mathrm{~B}(-)$ and height of $C(-)$ equals the overall area of the histogram below heq.

b. The performance of the mixing section was also evaluated by using statistical area weighted variance computations. The area weighted RMS values were calculated at $X / R=1$. Three different parameters (mixing deviations) - AMIX AHOT, and ACOLD—are described in Eqs 4 through 6.

AMIX $=\left[\frac{1}{A_{\text {tot }}} \sum_{j k} A_{j k}\left[\frac{T_{j k}-T_{\text {eq }}}{T_{\text {main }}-T_{\text {jet }}}\right]^{2}\right]^{\frac{1}{2}}$

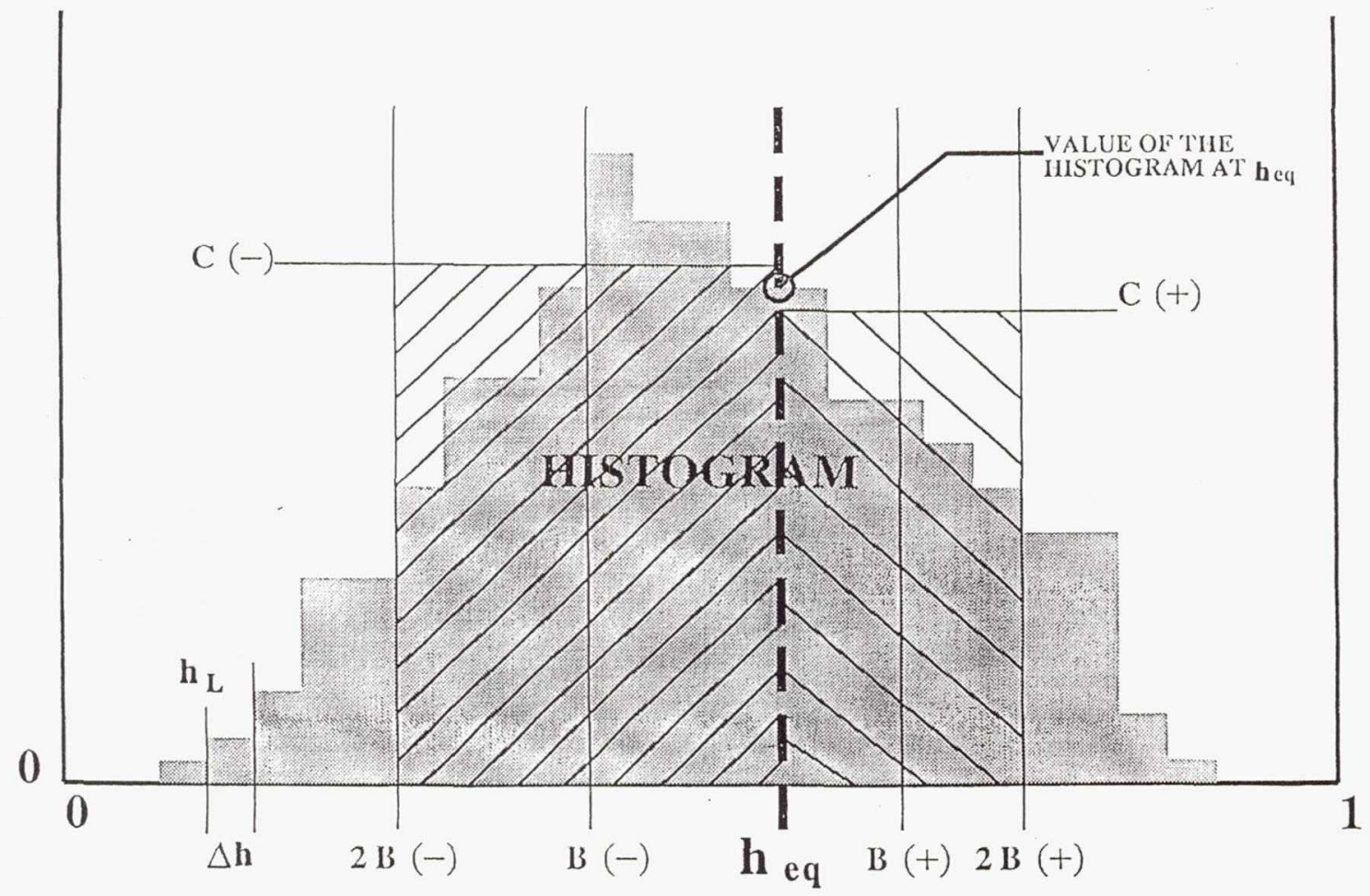

Figure 2. Graphical definition of the distribution function (DF), $B(+), B(-), C(+)$, and $C(-)$. 


$$
\begin{aligned}
& \text { AHOT }=\left[\frac{1}{A_{\text {tot }}} \sum_{j k} A_{j k}\left[\frac{T_{j k}-T_{e q}}{T_{\text {main }}-T_{j e t}}\right]^{2}\right]^{\frac{1}{2}} \text { for } T_{j k}>T_{e q} \\
& \text { ACOLD }=\left[\frac{1}{A_{\text {tot }}} \sum_{j k} A_{j k}\left[\frac{T_{j k}-T_{e q}}{T_{\text {main }}-T_{j e t}}\right]^{2}\right]^{\frac{1}{2}} \text { for } T_{j k}<T_{e q}
\end{aligned}
$$

From the definitions described in Figure 2, the best mixing is attained with the highest possible $\mathrm{C}(+)$ and $\mathrm{C}(-)$ and lowest possible $\mathrm{B}(+)$ and $\mathrm{B}(-)$. Similarly, the smallest deviation AMIX, AHOT, and ACOLD indicate the best mixing configuration. Note that AMIX is the square root of the sum of the squares of AHOT and ACOLD. The results described below are presented separately for each condition listed in Table 2. In this way, all geometric configurations with the same J also had the same MR and DR. The following four different parametric studies were performed:

- Effect of number of orifices. Quick mixing configurations with square orifices were analyzed with a single row of 6 , $8,10,12$, and 16 orifices. In addition, orifice configurations with the equilateral triangle (base upstream) were analyzed with 6,8 , and 12 orifices/row only at $J=20.55$. Higher J conditions were not analyzed in this study.

- Effect of slot aspect ratio. Five different slot aspect ratios were analyzed with a slot slant angle of $45 \mathrm{deg}$. The different slot aspect ratios are: $1,2,4,6$, and 8 . All mixing region configurations had a single row of 8 orifices.

- Effect of slot slant angle. Seven different slanted slot orientations were analyzed with a slot aspect ratio of 4 . The different slot slant angles are $0,15,30,45,60,75$, and 90 deg with respect to the center axis of the quick mixing region. All mixing configurations had a single row of 8 orifices.

- Effect of orifice shape. Seven different orifice shape configurations were analyzed: square, equilateral triangle (base downstream), equilateral triangle (base upstream), diamond, flow aligned slot, transverse slot, and continuous'(2-D) slot. All mixing region configurations had a single row of orifices, and the overall row ACd for all configurations was maintained constant at $849.5 \mathrm{~mm}^{2}$.

\section{$\underline{\text { Results for } \mathrm{I}=20.55}$}

\section{Effect of Number of Orifices on Mixing}

The results shown in Figure 3 indicate a significant decrease in jet penetration with increase of the number of orifices. The configurations with 12 orifices/row had a larger blockage fraction $(0.402)$ compared to 6 orifices/row (0.284). The blockage fraction of the jet orifice (Table 1) is defined as the circumferential projection of the orifice divided by the spacing between orifice centers. The blockage fraction indicates a value of the mainstream flow blockage produced by the jet at the location where the jet enters the mixing section. A higher blockage would effectively prevent the hot mainstream flow from occupying the volume immediately downstream of the orifice. Since the structure of the mixed flow in a cylindrical mixing section is highly area dependent, it is generally advantageous to have an orifice configuration with a higher blockage fraction to produce a more uniformly mixed flow structure toward the outer section of the mixing section. The enthalpy plot solutions indicate the coolest region behind the orifice for the configuration with 12 orifices/row, therefore, being the best mixing configuration. The statistical parameters also convey the same conclusion as the qualitative analysis as shown in Figure 8a. According to Holdeman (1991), the optimum number of orifices (n) in a can is shown in Eq 7. The optimum number of orifices calculated using Eq 7 for $\mathrm{J}=20.55$ is 8 .

$$
\mathrm{n}=\frac{\pi \sqrt{2 \mathrm{~J}}}{\mathrm{C}}
$$

where

$$
\mathrm{C}=2.50
$$

The jet penetration produced with the configuration with 8 orifices/row is significantly different compared to that of 6 orifices/row due to the change in jet flow structure near the center core of the mixing section. As the number of orifices increases, individual jets merge into a single structure that interacts differently with the mainstream flow. Although the jet penetration from a large number of smaller orifices is less than a smaller number of larger orifices, typically, configurations producing a merged jet structure have considerably less penetration compared to the configurations producing more distinct isolated jets. The jet penetration is affected by the high static pressure at the center core, especially when the hot core is virtually shielded from the rest of the mixing section due to the merged jet structure. This therefore inhibits the penetration of the merged jets as shown in Figure 3 for configurations with 8,10 , and 12 orifices/row. The statistical parameters indicate a significant increase in the mixing performance with the increase in the number of orifices/row, especially between 6 and 8 orifices/row. Both area and mass flux weighted parameters indicate similar trends.

The results for the equilateral triangles in Figure 4 seem to indicate a slight decrease in mixing performance with increasing number of orifices due to the rapid decrease in jet penetration. This trend, however, is opposite to the trend obtained with the square orifices. Based on these analytical results, the optimized triangular configuration at $I=20.55$ has 8 orifices/row.

\section{Effect of Slot Aspect Ratio}

The results shown in Figure 5 and $8 \mathrm{~b}$ indicate little improvement in the mixing performance with increase in slot aspect ratio from $\mathrm{L} / \mathrm{W}$ from 1 to 6 . Also note that the axial distance of injection increases with aspect ratio as shown in Table 1. A significant improvement was obtained by increasing the L/W to 8 , however both area and mass flux weighted parameters indicate similar results.

\section{Effect of Slot Slant Angle on Mixing}

The results shown in Figures 6 and $8 \mathrm{c}$ indicate a slight improvement in the mixing performance with increase in slot slant anglc. The mass flux weighted parameters indicate a higher sensitivity to the change in the slant angle compared to the area weighted parameters. The mass flux weighted parameters are significantly influenced by the value of the axial velocity distribution at plane $X / R=1$ and these results are influenced by the amount of swirl produced in the mixed flow structure. Furthermore, the amount of swirl imparted to the mixed flow depends on the slant angle. Highest swirl was produced with the 45-deg slant angle slot. Both 0-deg and 90-deg slanted slot configurations produced no swirl (as evidenced by the symmetric distribution in Figure 6). The 60-deg slant angle slot produced the best mixing at $\mathrm{J}=20.55$.

\section{Effect of Orifice Shape}

The results shown in Figure 7 indicate that optimum mixing performance is obtained with the configurations with the moderate jet penetration which are produced with both the square and triangle (base upstream) orifices. Excessively high jet penetration (such as the flow aligned slot) or low (such as the continuous [2-D] slot) pro-

\begin{tabular}{|c|c|c|c|c|c|c|c|}
\hline \multicolumn{8}{|c|}{ TABI.E.3. EFFECT OF ORIFICE SHAPE: ON MIXING FOR J=20.55, MR=0.96, AND DR=1.57 } \\
\hline ORIFICE CONTOUR & $\mathrm{B}(+)$ & $C(t)$ & $B(-)$ & $C(-)$ & AMIX & AHOT & ACOLD \\
\hline SQUARE & 0.119 & 0.101 & 0.098 & 0.151 & 0.157 & 0.14 & 0.07 \\
\hline TRNGi BASE UPST & 0.237 & 0.06 & 0.165 & 0.067 & 0.213 & 0.188 & 0.099 \\
\hline TRNG BASE DWNST & 0.124 & 0.088 & 0.089 & 0.16 & 0.129 & 0.15 & 0.076 \\
\hline DIAMOND & 0.18 & 0.073 & 0.165 & 0.072 & 0.19 & 0.156 & 0.108 \\
\hline SLOT $\phi=0 \mathrm{deg}$ & 0.215 & 0.063 & 0.165 & 0.07 & 0.202 & 0.164 & 0.118 \\
\hline SLOT $\phi=90 \mathrm{deg}$ & 0.155 & 0.066 & 0.09 & 0.162 & 0.17 & 0.135 & 0.10 .3 \\
\hline 2.D SI.OT & 0.395 & 0.021 & 0.325 & 0.031 & 0.391 & 0.313 & 0.235 \\
\hline
\end{tabular}
duce nonoptimal cases. The statistical results are shown in Table 3 .

Table 3 .

Effect of orifice shape on mixing for $J=20.55, \mathrm{MR}=0.96$, and $\mathrm{DR}=1.57$. 
Page intentionally left blank 


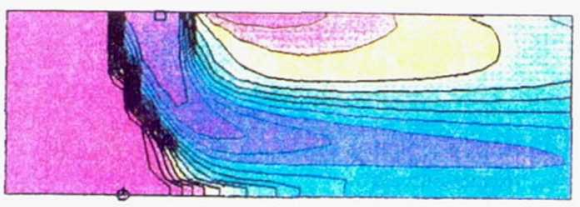

6 ORIFICES / ROW

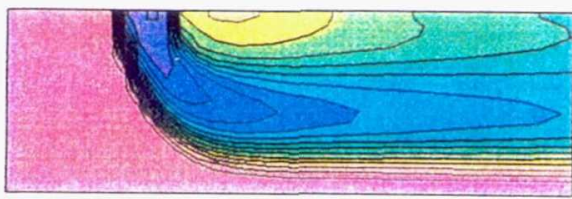

10 ORIFICES / ROW

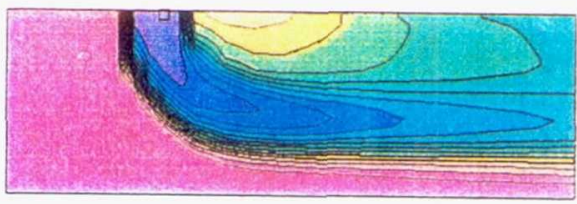

8 ORIFICES / ROW

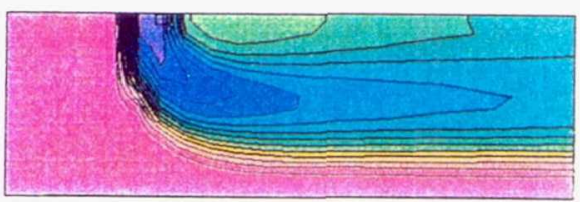

12 ORIFICES / ROW

a. Axial-radial plane through orifice center
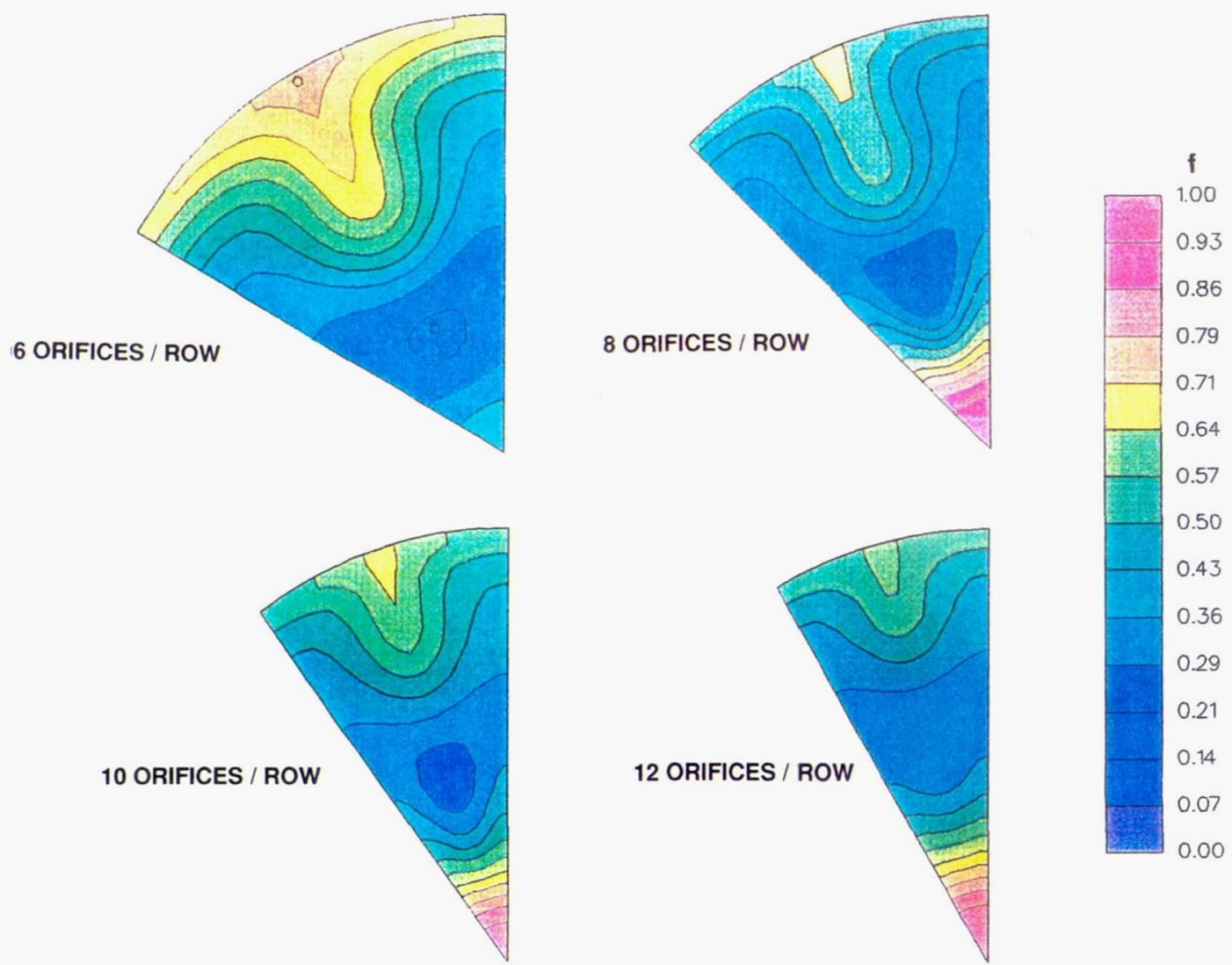

\section{b. Radial-tangential plane} at $X / R=1$

Figure 3. Effect of the number of square orifices on mixing for $\mathrm{J}=20.55, \mathrm{MR}=0.96, \mathrm{DR}=1.57$, $h_{\text {eq }}=0.510$. 
Page intentionally left blank 


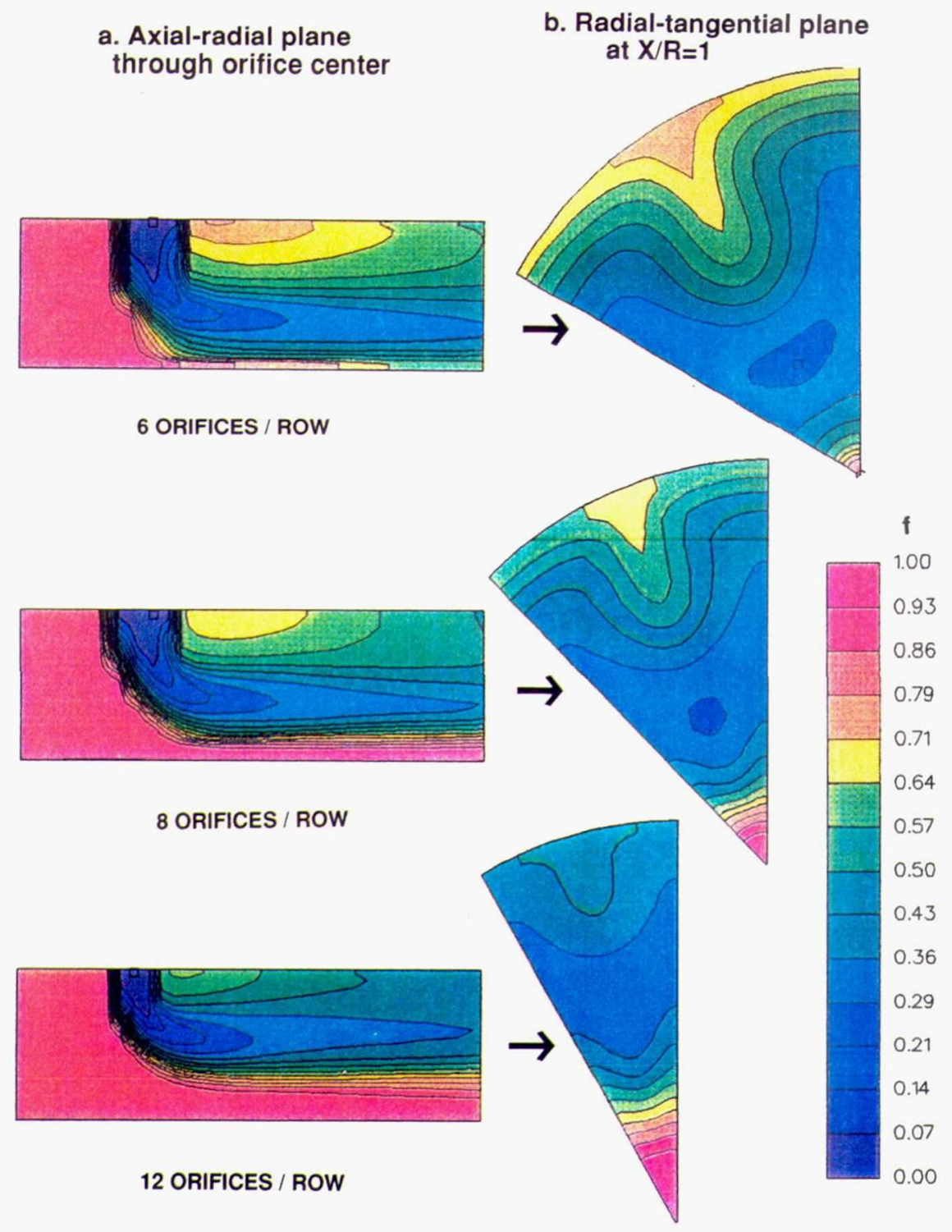

Figure 4. Effect of the number of triangular orifices on mixing for $\mathrm{J}=20.55, \mathrm{MR}=0.96, \mathrm{DR}=1.57$, heq $=0.510$. 
Page intentionally left blank 


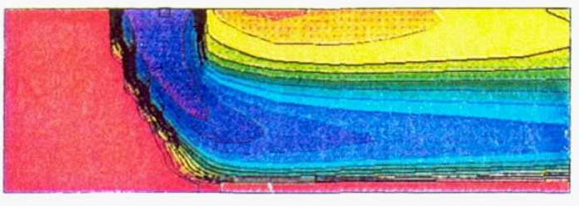

$\mathrm{L} / \mathrm{W}=1$

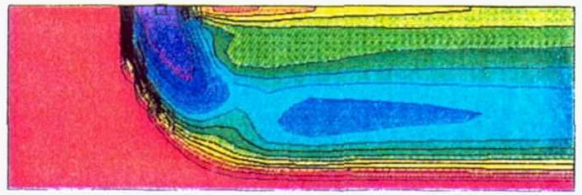

$\mathrm{L} / \mathrm{W}=2$

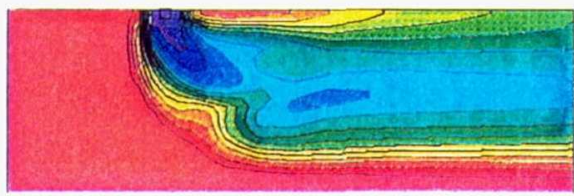

$\mathrm{L} / \mathrm{W}=4$

a. Axial-radial plane through orifice center
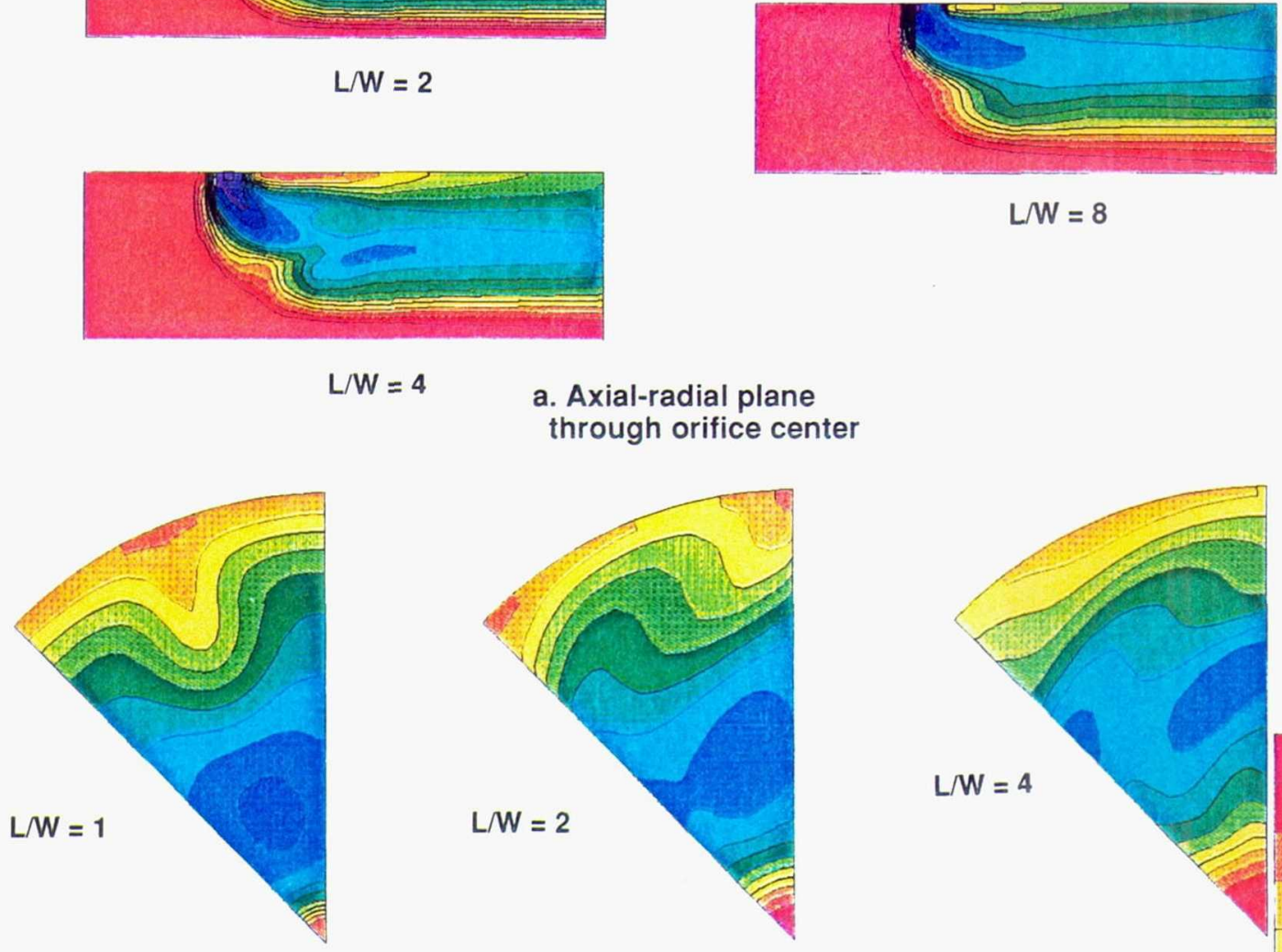

$L / W=8$

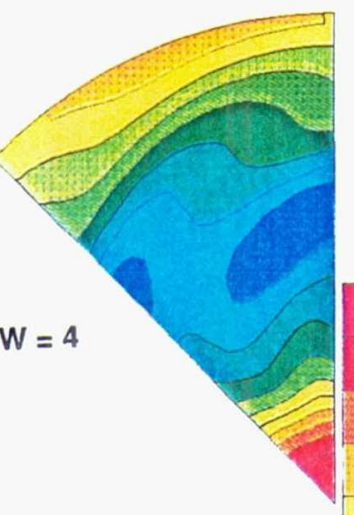

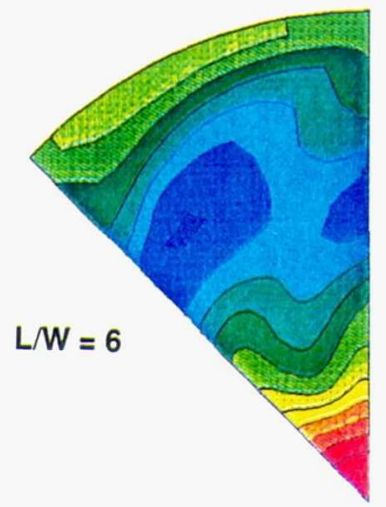
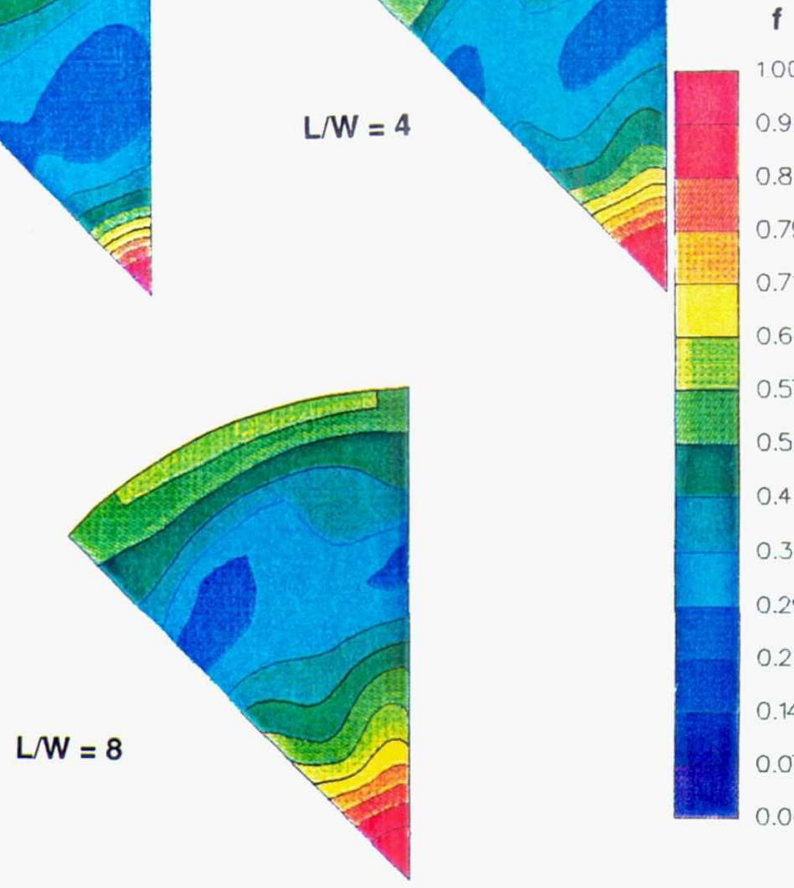

100

\section{b. Radial-tangential plane at $X / R=1$}

Figure 5. Effect of slot aspect ratio $(\mathrm{L} / \mathrm{W})$ on mixing for $\mathrm{J}=20.55, \mathrm{MR}=0.96, \mathrm{DR}=1.57$, slang angle $=$ $45 \mathrm{deg}, \mathrm{h}_{\text {eq }}=0.510$. 
Page intentionally left blank 


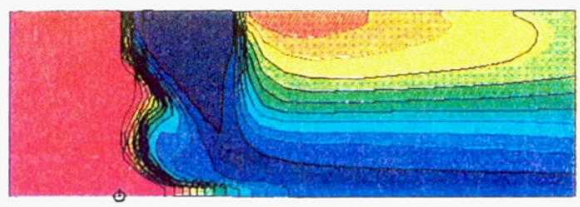

$\phi=0^{\circ}$

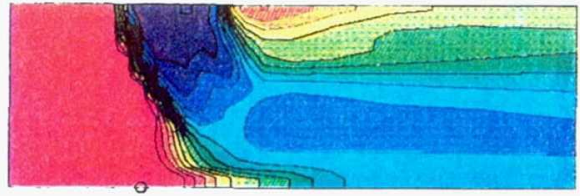

$\phi=15^{\circ}$

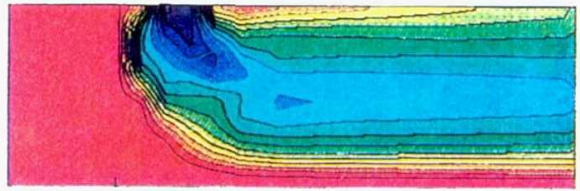

$\phi=30^{\circ}$
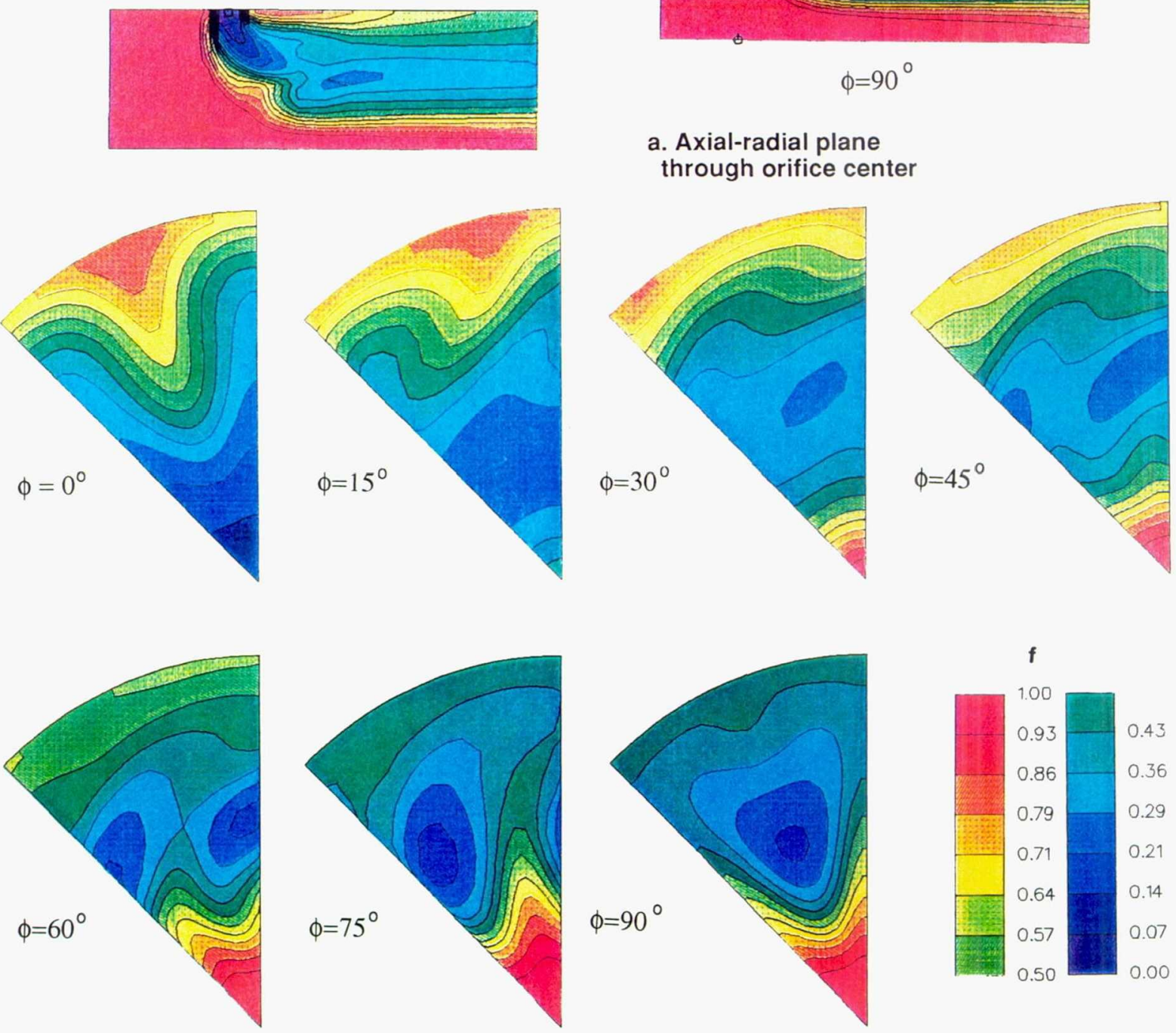

NORMALIZED ENTHALPY

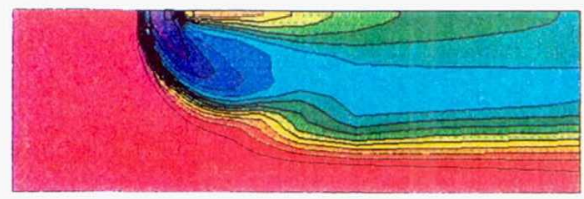

$\phi=60^{\circ}$

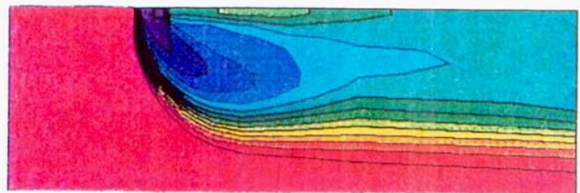

$\phi=75^{\circ}$

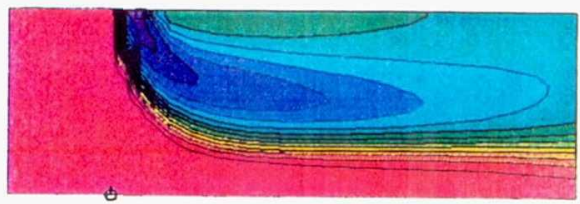

$$
\phi=90^{\circ}
$$

a. Axial-radial plane through orifice center
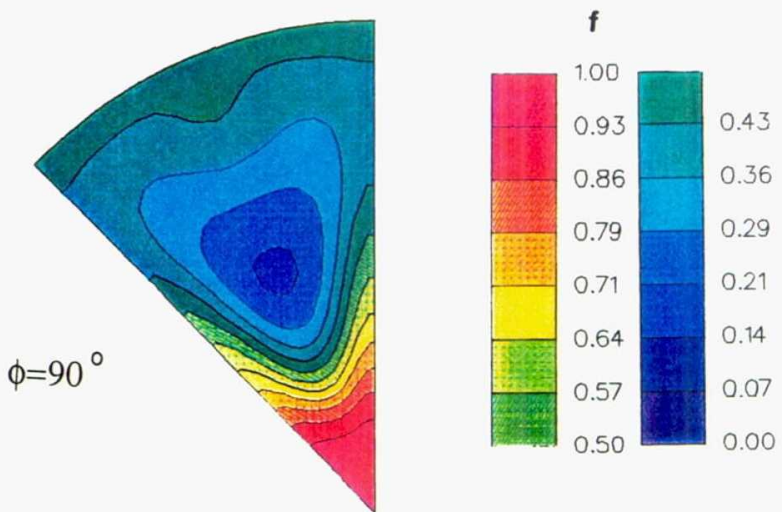

\section{b. Radial-tangential plane at $X / R=1$}

Figure 6. Effect of slot slant angle on mixing for $\mathrm{J}=20.55, \mathrm{MR}=0.96, \mathrm{DR}=1.57, \mathrm{~L} / \mathrm{W}=4, \mathrm{~h}$ eq $=0.510$. 
Page intentionally left blank 


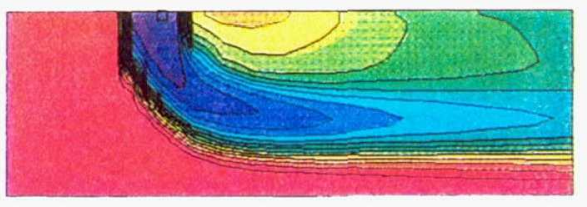

SQUARE

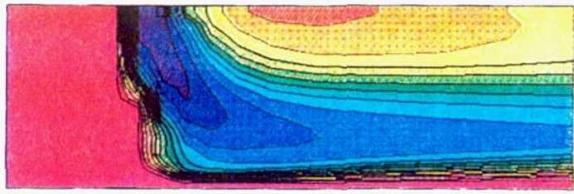

TRIANGLE (BASE DOWNSTREAM)

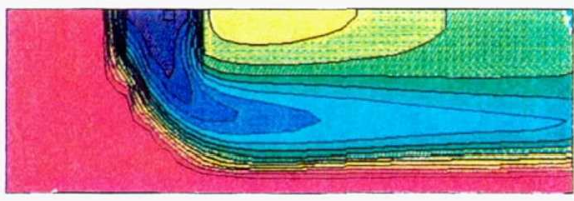

TRIANGLE (BASE UPSTREAM)

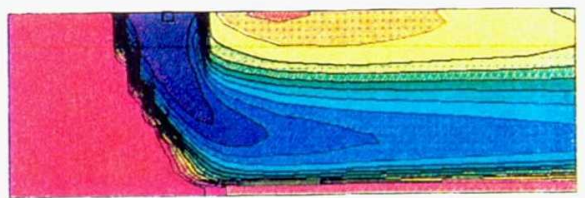

DIAMOND (SLOT L/H=1.0)
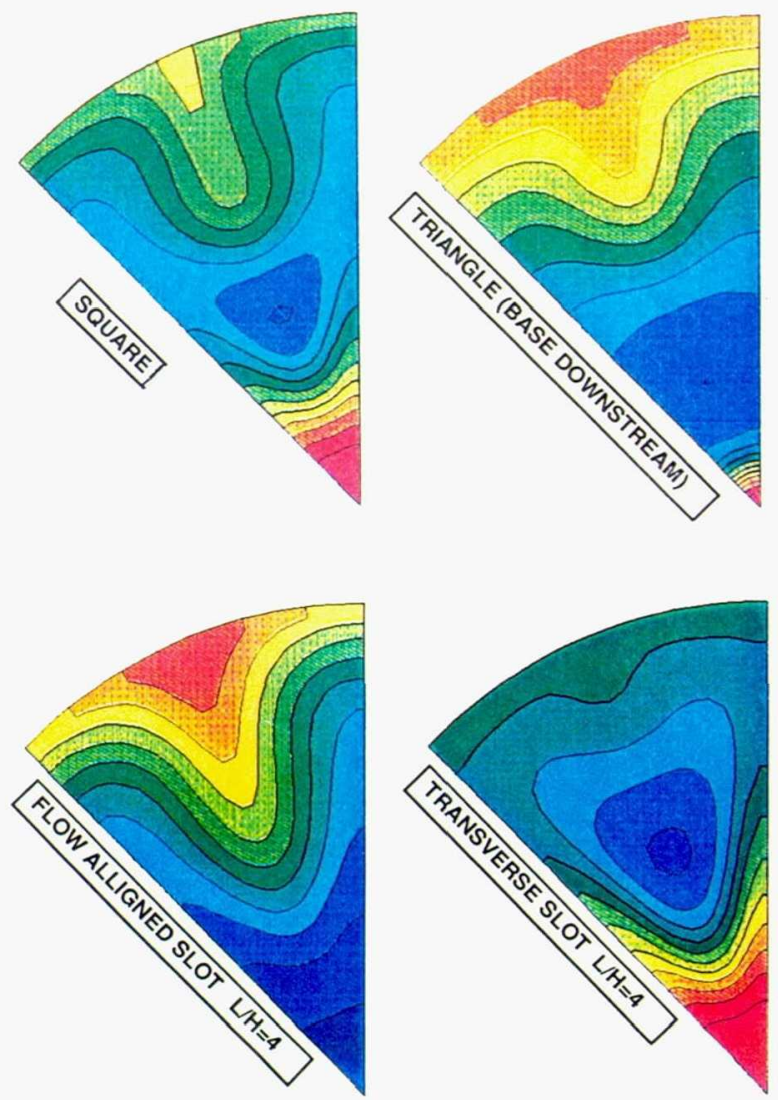

\section{b. Radial-tangential plane} at $X / R=1$
NORMALIZED ENTHALPY

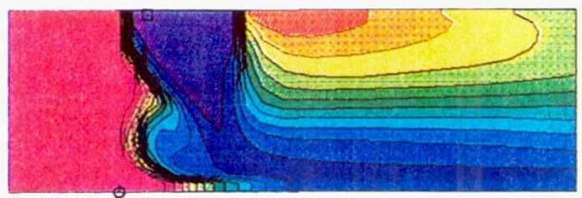

FLOW ALLIGNED SLOT $\quad$ L/H=4

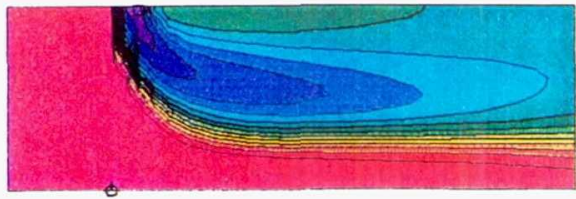

TRANSVERSE SLOT $\mathrm{L} / \mathrm{H}=4$

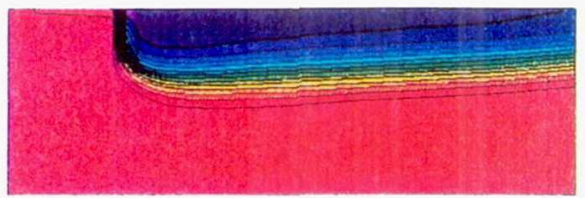

CONTINUOUS SLOT L/H=7.42

a. Axial-radial plane through orifice center
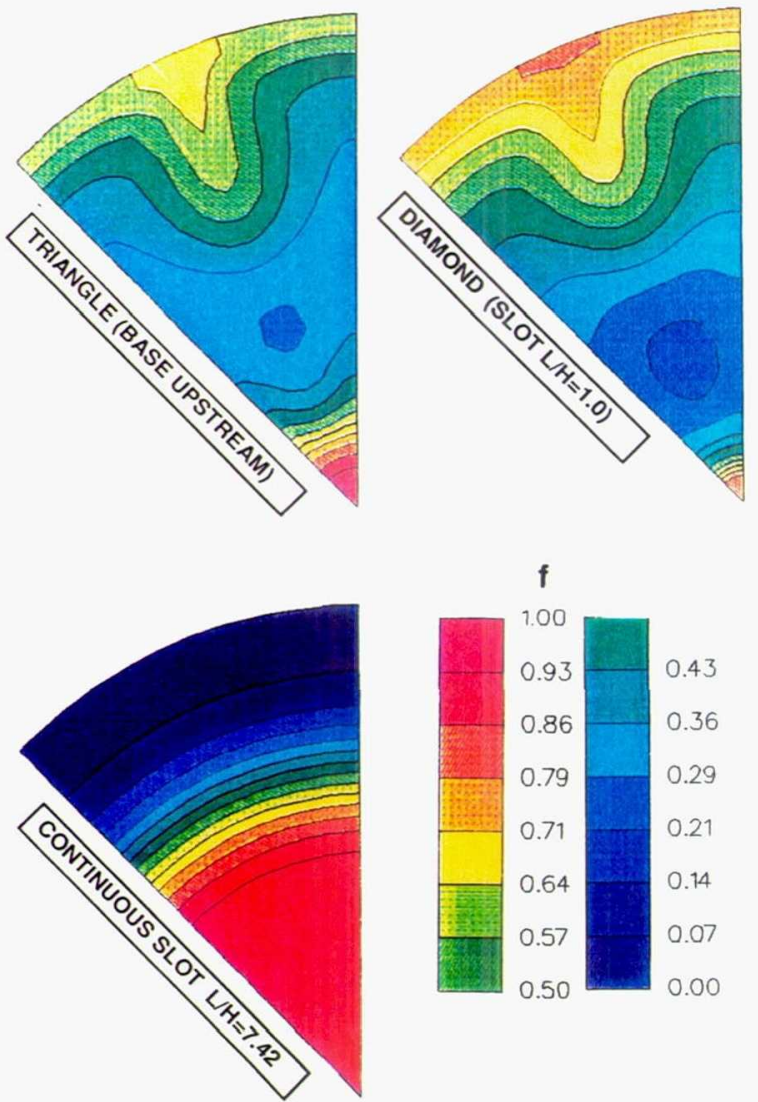

Figure 7. Effect of orifice shape on mixing for $\mathrm{J}=20.55, \mathrm{MR}=0.96, \mathrm{DR}=1.57, \mathrm{~h}_{\mathrm{eq}}=0.510$. 
Page intentionally left blank 
a.
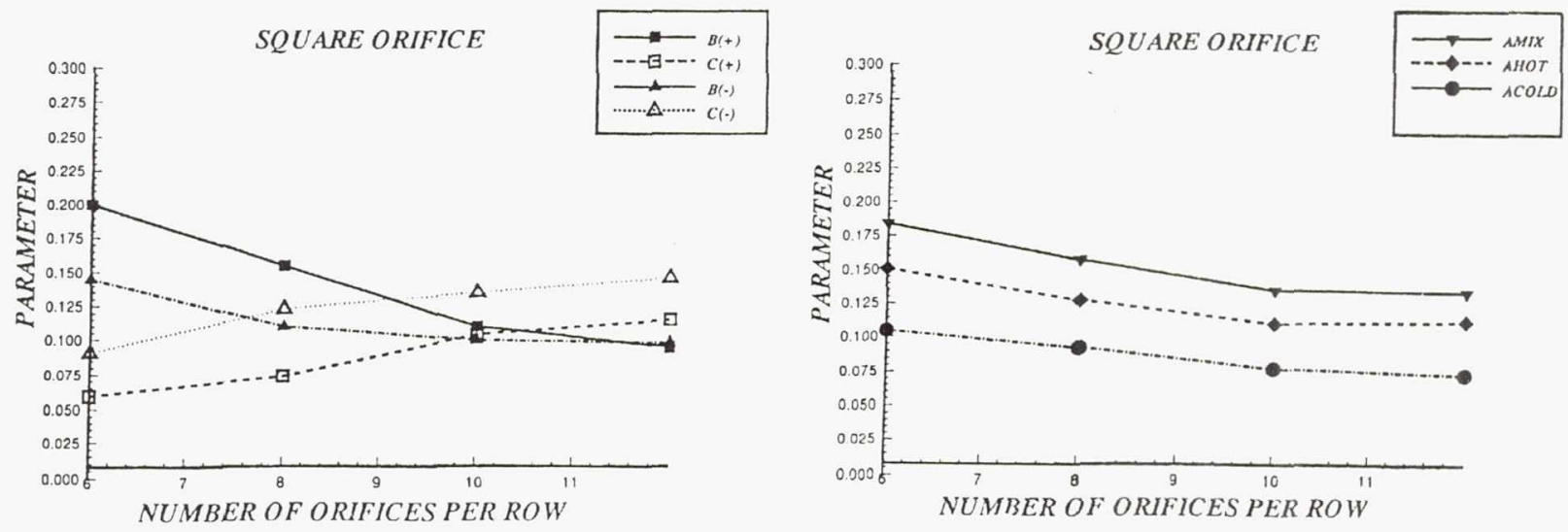

b.
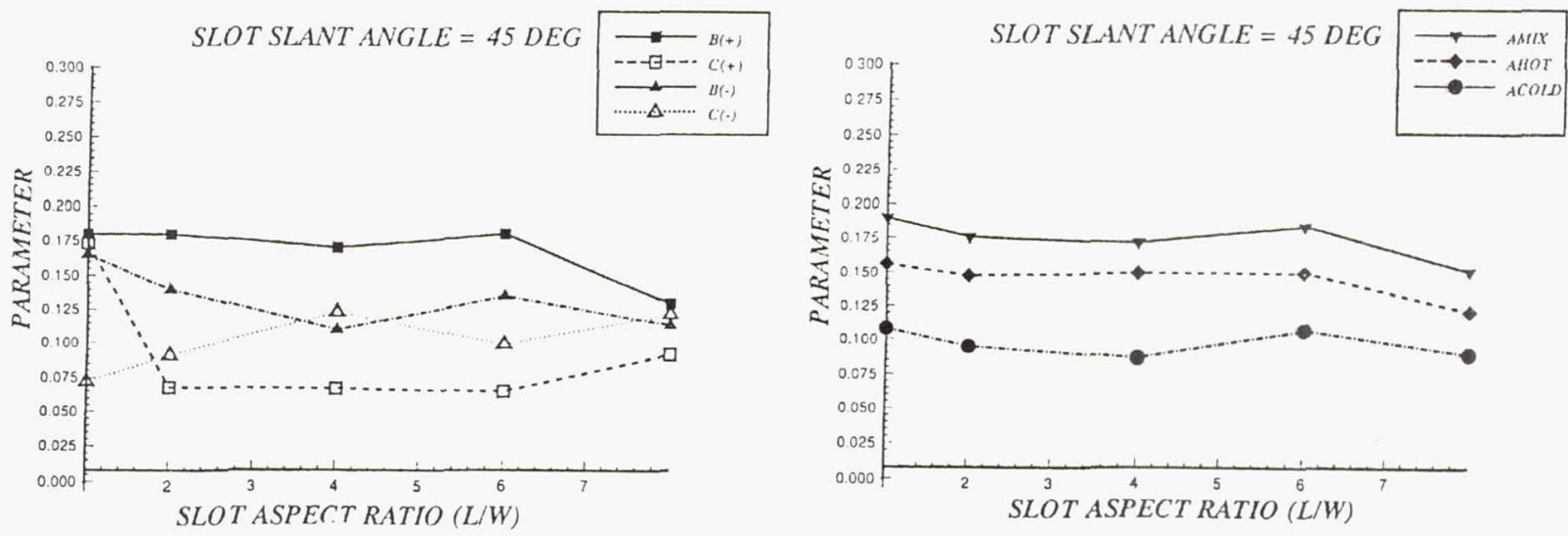

c.
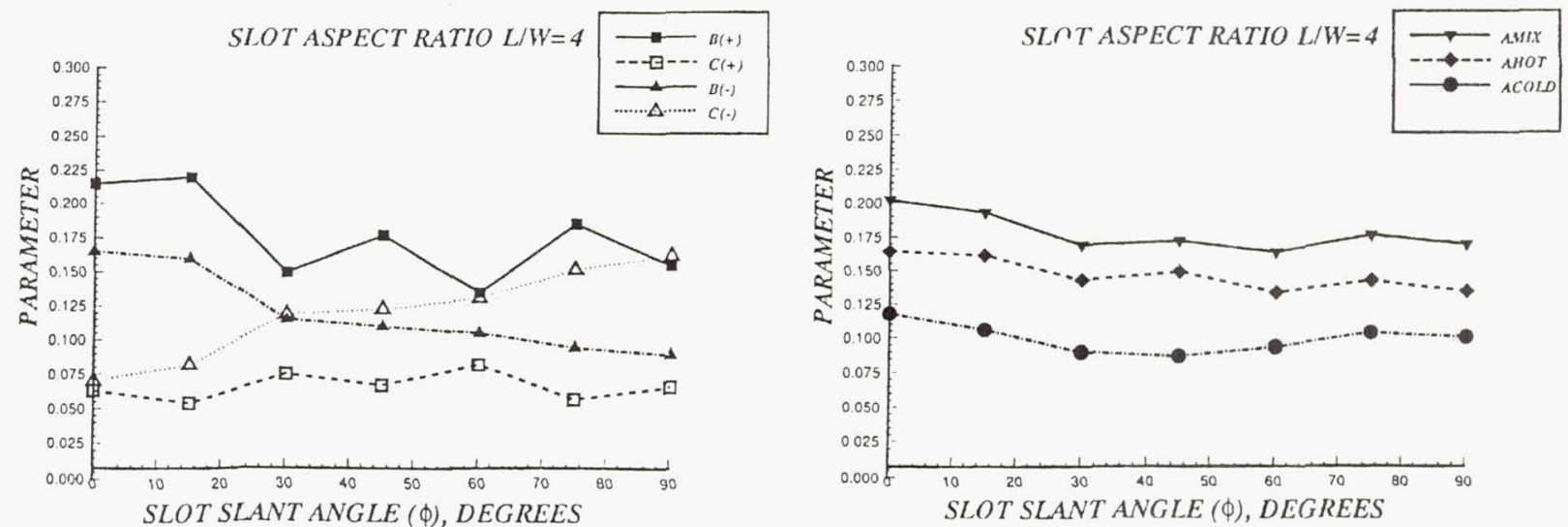

Figure 8. Statistical results of the parametric study at $\mathrm{J}=20.55, \mathrm{MR}=0.96$, and $\mathrm{DR}=1.57$. 


\section{$\underline{\text { Results for } I=36.50}$}

\section{Effect of Number of Orifices}

Both visual and statistical analyses shown in Figures 9 and 12a indicate an improvement in mixing with increase in the number of orifices. The increase in number of orifices increases the blockage fraction and reduces the mainstream hot gas recirculation behind the orifice. This produces a more uniform temperature distribution behind the mixing orifice at the expense of a hot unmixed center core. Both area weighted and mass flux weighted parameters indicate the same conclusion. The optimum number of orifices calculated with Eq 7 yields 11 orifices/row, which also agrees with the present results.

\section{Effect of Slot Aspect Ratio}

The results are shown in Figures 10 and $12 \mathrm{~b}$. These results show a significant improvement in mixing with increase in slot aspect ratio. The statistical results indicate an almost direct relationship between mixing improvement and increase in slot aspect ratio despite the fact that large $L / W$ injects the mixing airflow over a longer axial distance. Optimum performance was obtained with the $\mathrm{L} / \mathrm{W}=8$ slot. Both area weighted and mass flux weighted parameters indicated the same conclusion. Since the statistical parameters are all highly area weighted, increased performance can be obtained by reducing the over-penetration of the $\mathrm{L} / \mathrm{W}=1$ slot at the expense of producing a hot center core as shown for $\mathrm{L} / \mathrm{W}=8$. However, the hot core in the center occupies a small portion (less than $5 \%$ ) of the total area in the plane at $X / R=1$, and this does not significantly affect the statistical results.

\section{Effect of Slot Slant Angle}

The results shown in Figures 11 and $12 \mathrm{c}$ indicate better mixing is produced with the larger slant angle configurations. As jet penetration decreases with increase in slot slant angle, the area toward the outer wall of the mixing section becomes cooler and therefore increases the temperature uniformity. In addition, increase in slot slant angle up to $45 \mathrm{deg}$ produces increased counterswirling flows, which stratify the temperature distribution in the radial direction and inhibit the entrainment of cold jet flow in the region behind the orifice. Some deviation was obtained between the area weighted and the mass flux weighted results. The mass flux weighted parameters are sensitive in areas where the axial velocity distribution is nonuniform, therefore, being highly dependent on the jet penetration region (where the velocity and gradients are high). The mass flux weighted parameters, unlike the simple area weighted averages, more accurately reflect the mixing tendency in areas where the flow gradients are high. Best mixing tendencies were obtained with either the 75- or 90-deg slant angle slots due to the best combination of optimum jet penetration, and low recirculation strength, and high blockage fraction.

Results for $I=82.18$

\section{Effect of Number of Orifices}

The results are shown in Figures 13 and 16a. The best performance was obtained with 16 orifices/row at this high J mostly due to a significant reduction in the jet penetration. Configurations with 812 orifices overpenetrated due to the high $\mathrm{J}$ condition. These results are not surprising since results using Eq 7 indicate an optimum number of orifices of 16 at $J=82.18$.

\section{Effect of Slot Aspect Ratio}

The results are shown in Figures 14 and 16b. The results indicate an optimum mixing performance with the large aspect ratio slot $\mathrm{L} / \mathrm{W}=8$. The increase in slot aspect ratio decreases the jet penetration as shown previously for the lower $\mathrm{J}$ conditions. Overpenetration is produced with the slot with aspect ratio of $\mathrm{L} / \mathrm{W}=4$ and a high temperature nonuniformity is also observed due to the high temperature entrained behind the orifice. The area weighted parameters, which are nonvelocity dependent, show a different trend compared to the mass weighted parameters. This is due to the high velocity gradients produced by the swirling flows which are highest for the aspect ratio orifice $(\mathrm{L} / \mathrm{W}=4)$. After incorporating the velocity effect into the area weighted parameters, the results were similar in trend to the distribution function mass weighted parameters.

\section{Effect of the Slot Slant Angle}

The results are shown in Figures 15 and $16 c$. The results indicate a similar trend as described in the lower J configurations. Increased mixing performance was obtained with the large slant angle; however, the optimum configuration producing best mixing was the configuration with the 75-deg slanted slot. Slanted slot configuration with up to 45-deg slant produced overpenetration at this high J; therefore, hot mainstream flow was entrained behind the orifice and produced an undesirable mixing structure.

\section{Conclusions}

1. The best orifice configuration depends significantly on the penetration depth of the jet to prevent the hot mainstream flow from being entrained behind the orifice. Orifices producing strong swirl in the mixing region have an adverse effect due to the temperature stratification toward the outer wall.

2. The simple area weighted statistical parameters correlate well with the mass flux weighted parameters in almost all analyzed configurations. Differences were found however in flow structures where swirls were high and axial velocity distributions contain high gradients. In such cases, the area weighted parameters are somewhat deficient in quantifying the mixing tendency. The flow structure in a circular mixing section is highly weighted toward the outer wall and any flow structure affecting this area significantly affects the overall results.

3. The increase in the number of orifices per row increases the mixing performance for low $\mathrm{J}$ due to the increase in the orifice blockage fraction. Significant mixing improvement was also attributed to the merging tendency of the individual jets in a circular domain. Jet overpenetration produced nonoptimal mixing configurations.

4. Higher slot slant angles and aspect ratios are generally the best mixing configurations at higher J conditions. However, at the lowest J conditions analyzed in this study, the square and triangular orifices have better mixing. Therefore the design of the quick mixing section strongly depends on the operating condition of the combustion liner (DP/P and or J) and these conditions must be known a priori before selecting the appropriate orifice configuration for best mixing.

\section{References}

Hatch, M.S., Sowa, W.A., Samuelsen, G.S., and Holdeman, J.D., "Jet Mixing Into a Heated Cross Flow in a Cylindrical Duct: Influence of Geometry and Flow Variations," AIAA paper No. AIAA-92-0773, 30th Aerospace Sciences Meeting \& Exhibit, Jan 1992 (NASA TM 105390).

Holdeman, J.D., "Mixing of Multiple Jets With a Confined Subsonic Crossflow," AIAA paper number 91-2458, June 1991 (NASA TM 104412).

Launder, B.E., and Spalding, D.B., "The Numerical Computation of Turbulent Flows," Comp. Methods Appl. Mech. Eng., Vol 3, pp 269-89.

Mongia, H.C., and Reynolds, R.S., "Combustor Design Criteria Validation," Vol III, USARTL-TR-78-55C, Feb 1979.

Patankar, S.V., "Numerical Heat Transfer and Fluid Flows," Hemisphere, Washington, D.C., 1980. 
a. Axial-radial plane
through orifice center

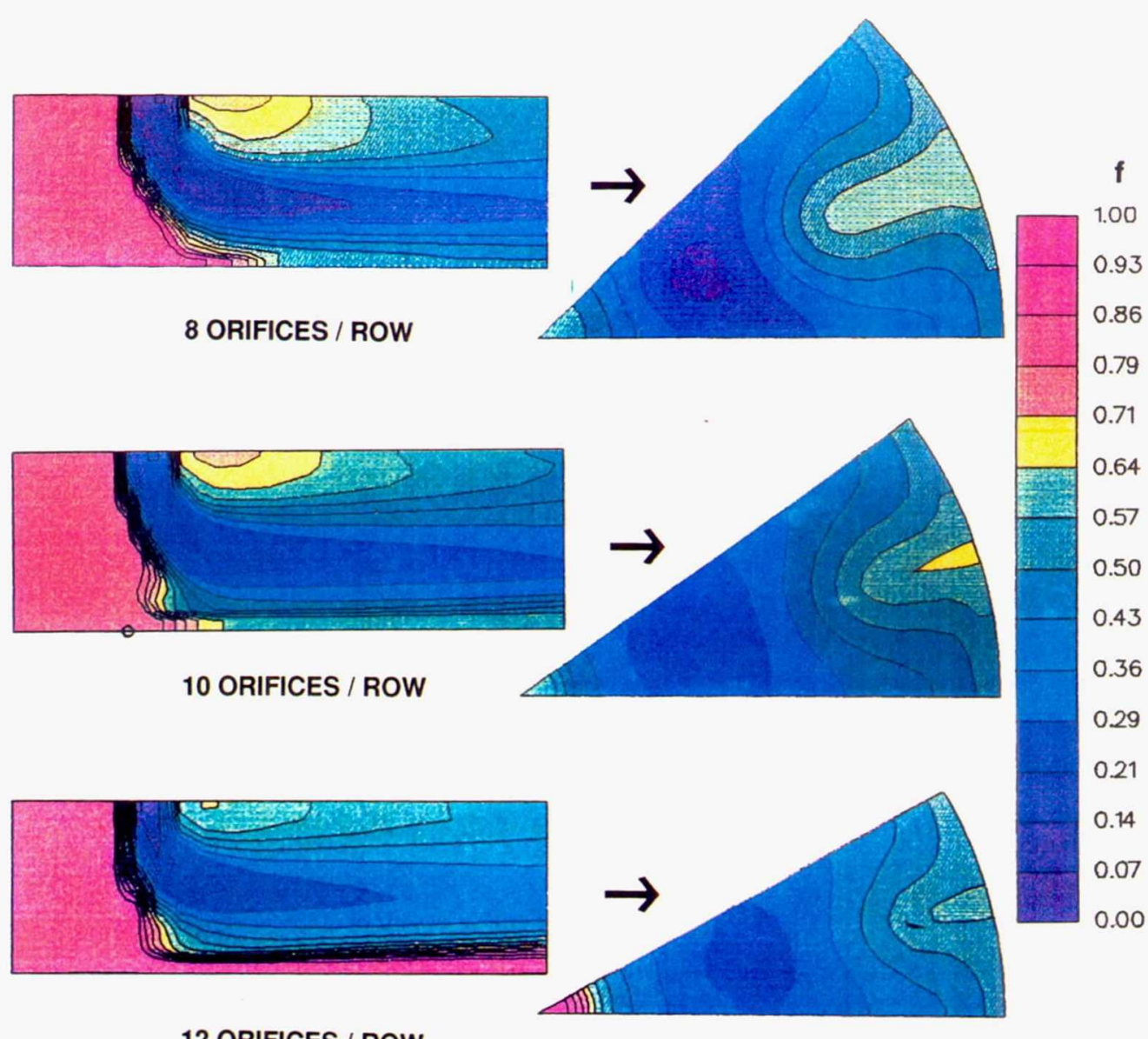

12 ORIFICES / ROW b. Radial-tangential plane at $X / R=1$

.93

.86

79

.71

0.64

0.57

0.50

0.43

0.36

0.29

0.21

0.14

0.07

0.00

Figure 9. Effect of the number of square orifices on mixing for $\mathrm{J}=36.55, \mathrm{MR}=1.28, \mathrm{DR}=1.57$,

$$
h_{\text {eq }}=0.439 \text {. }
$$

Rizk, N.K., and Mongia, H.C., "Ultra-Low $\mathrm{NO}_{\mathrm{x}}$ Rich Lean Combustion," ASME paper No. 90-GT-87, 1990.

Rizk, N.K., and Mongia, H.C., "Low NO $\mathrm{N}_{\mathrm{x}}$ Rich-Lean Combustion Concept Application," AIAA paper No. 91-1962, June 1991.

Smith, C.E., Talpallikar, M.V., and Holdeman, J.D., "A CFD Study of Jet Mixing in Reduced Flow Areas for Lower Combustion Emissions," AIAA paper No. 91-2460, June 1991 (NASA TM 104411).
Talpallikar, M.V., Smith, C.E., Lai, M.C., and Holdeman, J.D., "CFD Analysis of Jet Mixing in Low $\mathrm{NO}_{x}$ Flametube Combustors," June 1991 (NASA TM 104466).

Vranos, A., Liscinsky, D.S., True, B., and Holdeman, J.D., "Experimental Study of Cross-Stream Mixing in a Cylindrical Duct," AIAA paper No. 91-2459, June 1991 (NASA TM 105180). 
Page intentionally left blank 


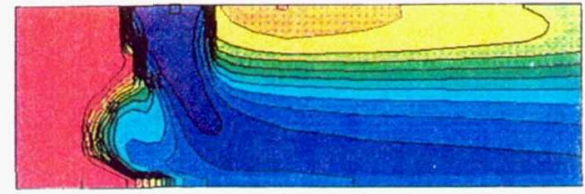

$\mathrm{L} / \mathrm{W}=1$

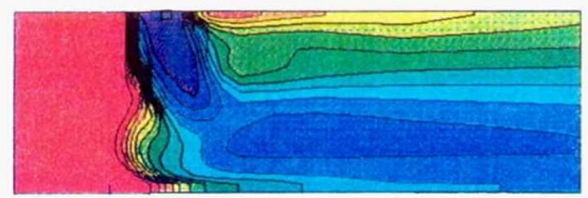

$\mathrm{L} / \mathrm{W}=2$

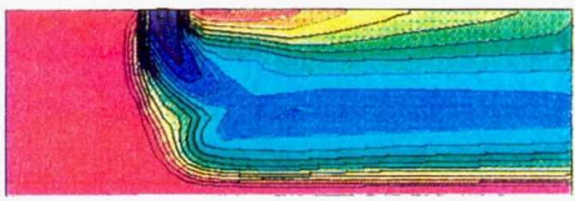

$\mathrm{L} / \mathrm{W}=4$

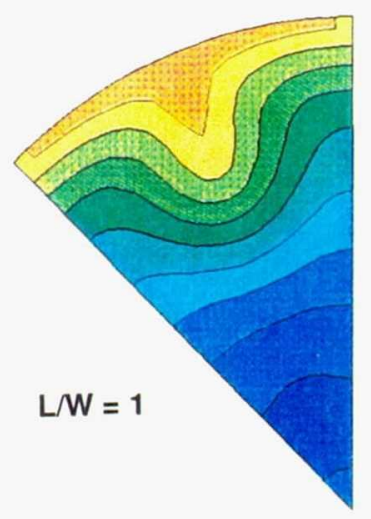

a. Axial-radial plane through orifice center
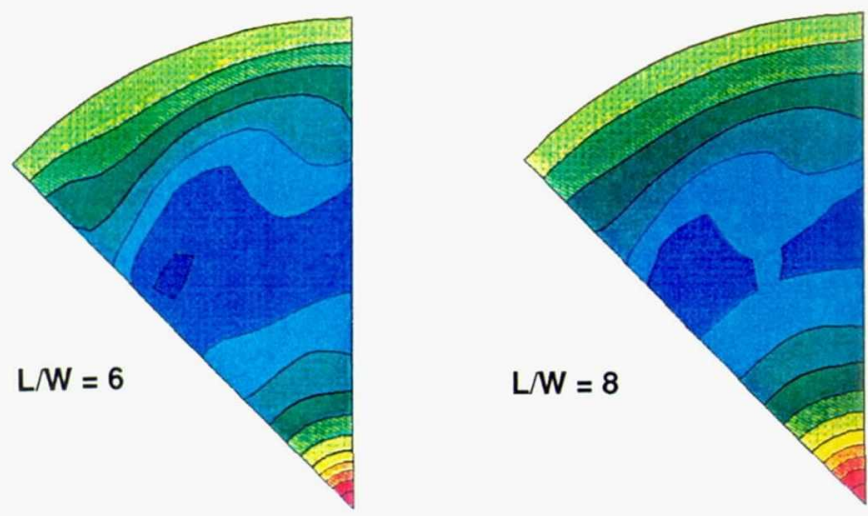

$$
\mathrm{L} / \mathrm{W}=8
$$

$$
L / W=6
$$$$
\mathrm{LW}=8
$$
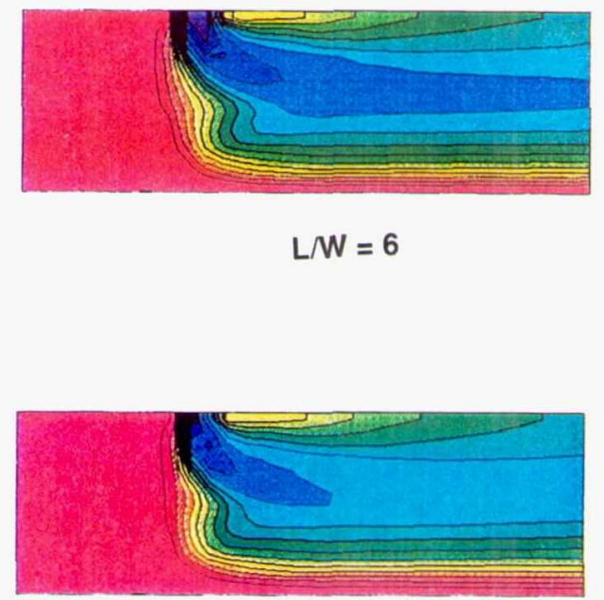
Page intentionally left blank 


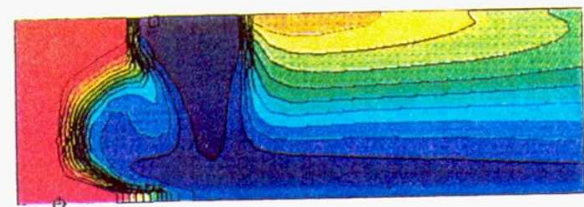

$\phi=0^{\circ}$

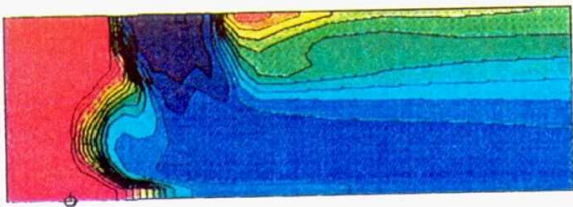

$\phi=15^{\circ}$

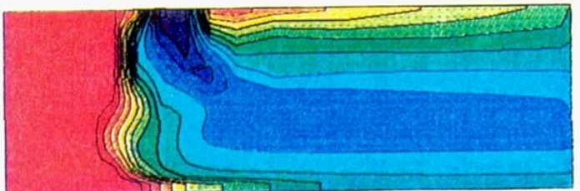

$\phi=30^{\circ}$

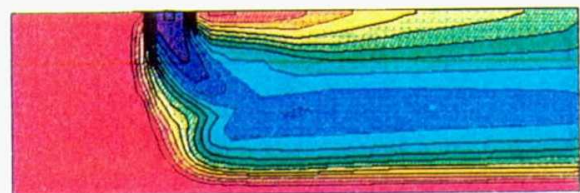

$\phi=45^{\circ}$

NORMALIZED ENTHALPY

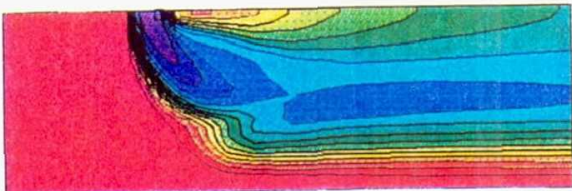

$\phi=60^{\circ}$

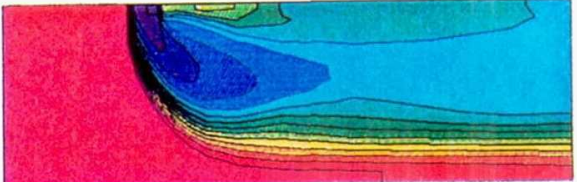

$\phi=75^{\circ}$

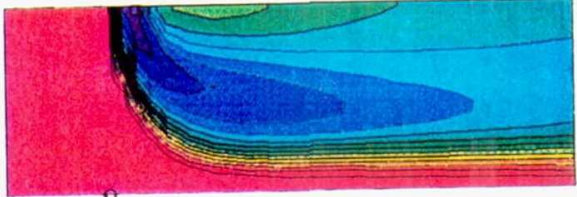

$$
\phi=90^{\circ}
$$

a. Axial-radial plane through orifice center
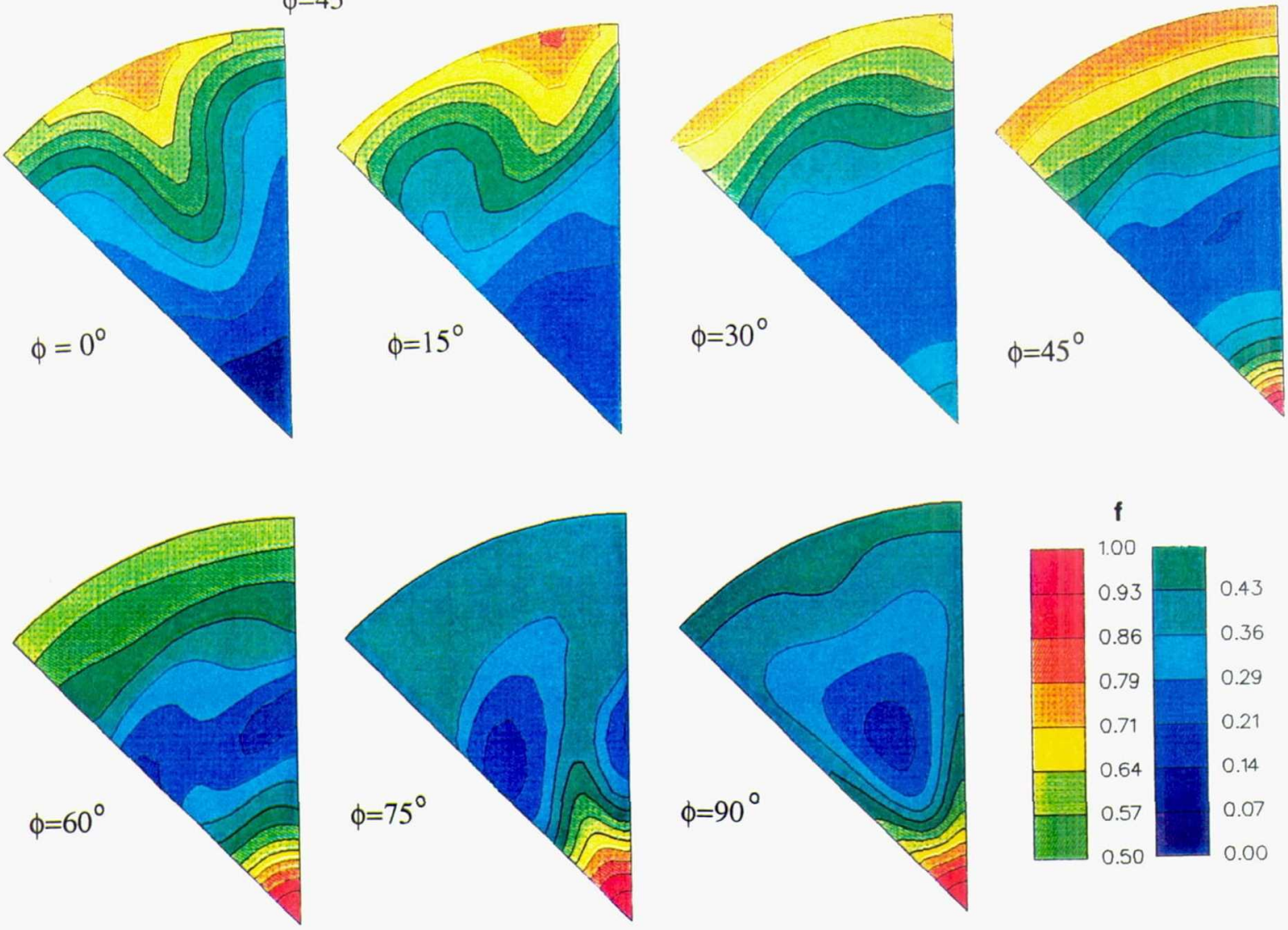

\section{b. Radial-tangential plane at $X / R=1$}

Figure 11. Effect of slot slant angle on mixing for $\mathrm{J}=36.55, \mathrm{MR}=1.28, \mathrm{DR}=1.57, \mathrm{~L} / \mathrm{W}=4, \mathrm{~h}_{\mathrm{eq}}=0.439$. 
Page intentionally left blank 


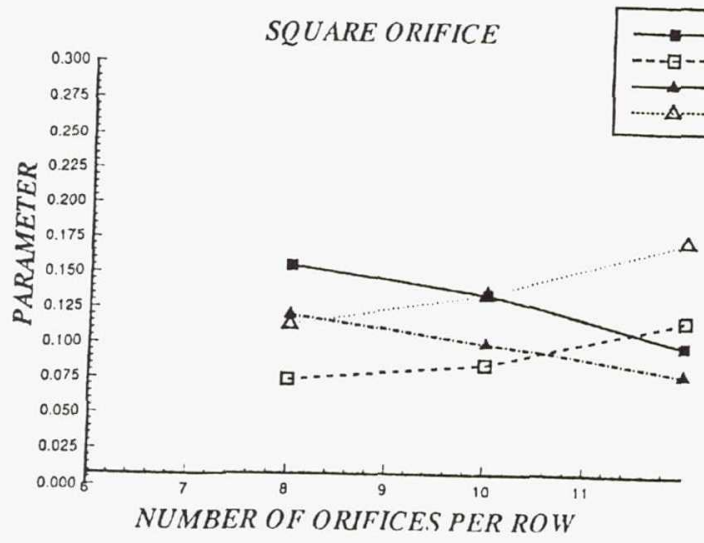

b.

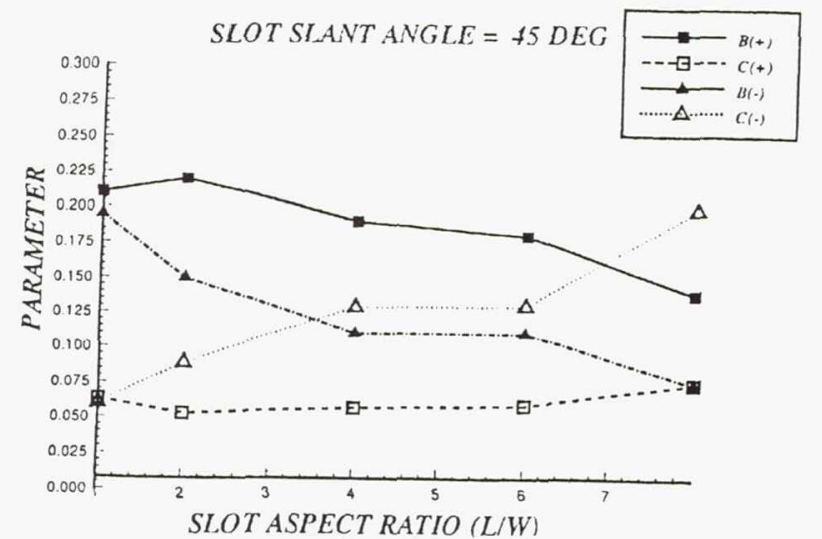

c.

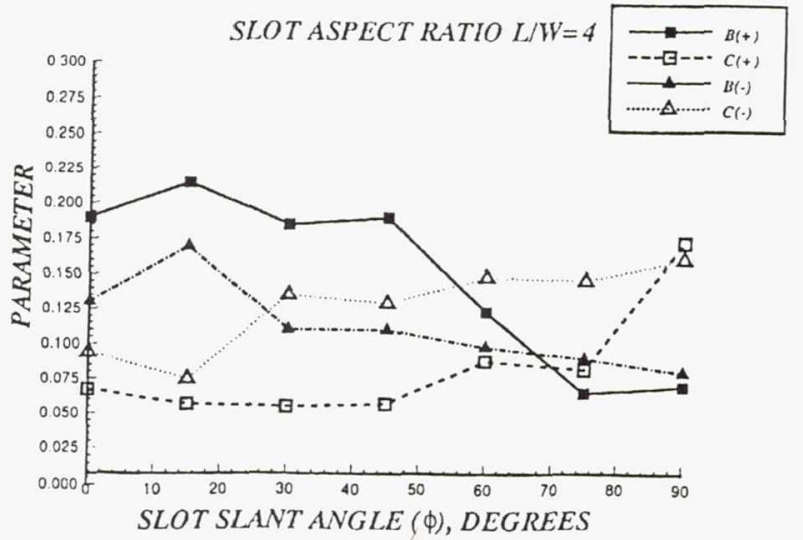

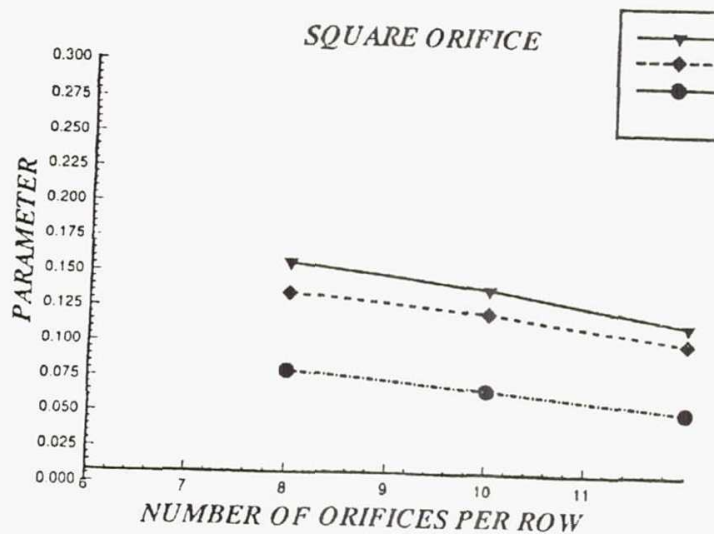
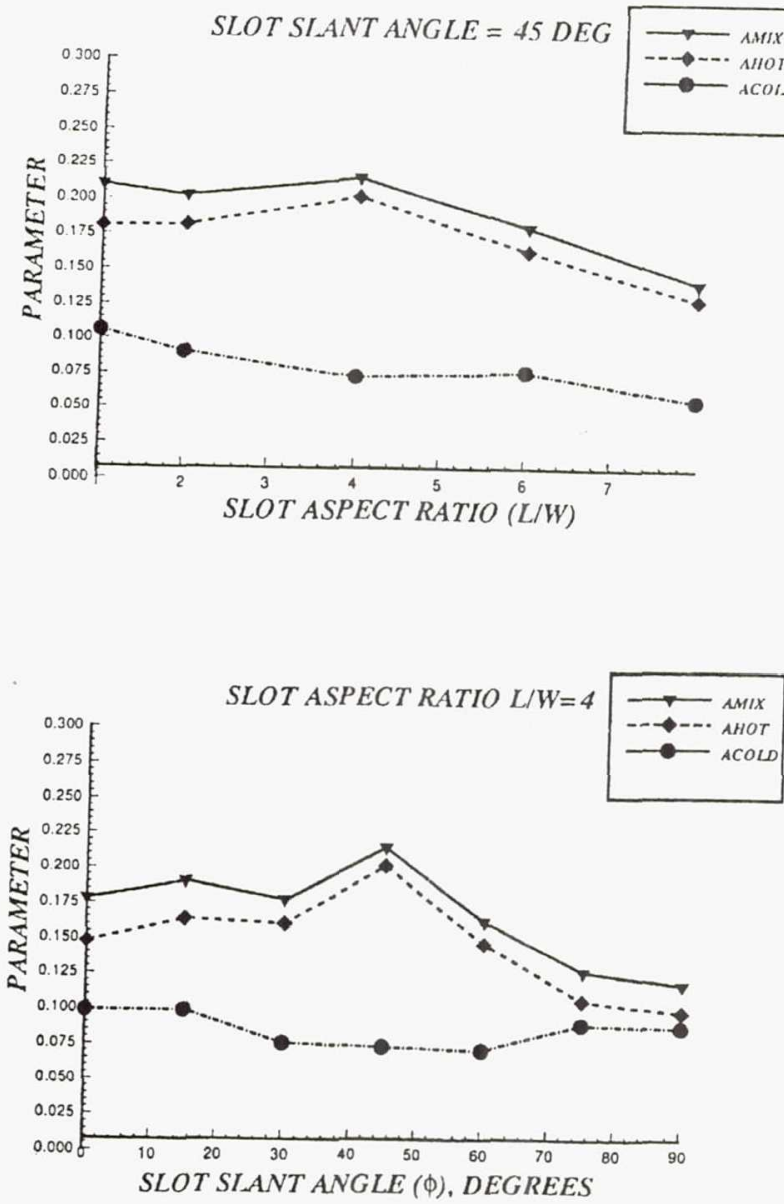

Figure 12. Statistical results of the parametric study at $J=36.55, M R=1.28$, and $D R=1.57$. 
Page intentionally left blank 
a. Axial-radial plane through orifice center

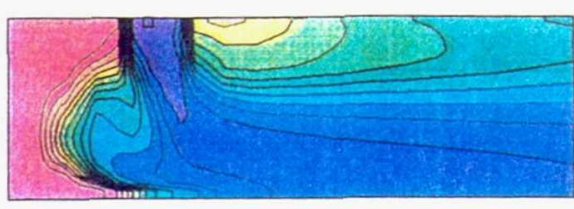

8 ORIFICES / ROW b. Radial-tangential plane at $X / R=1$
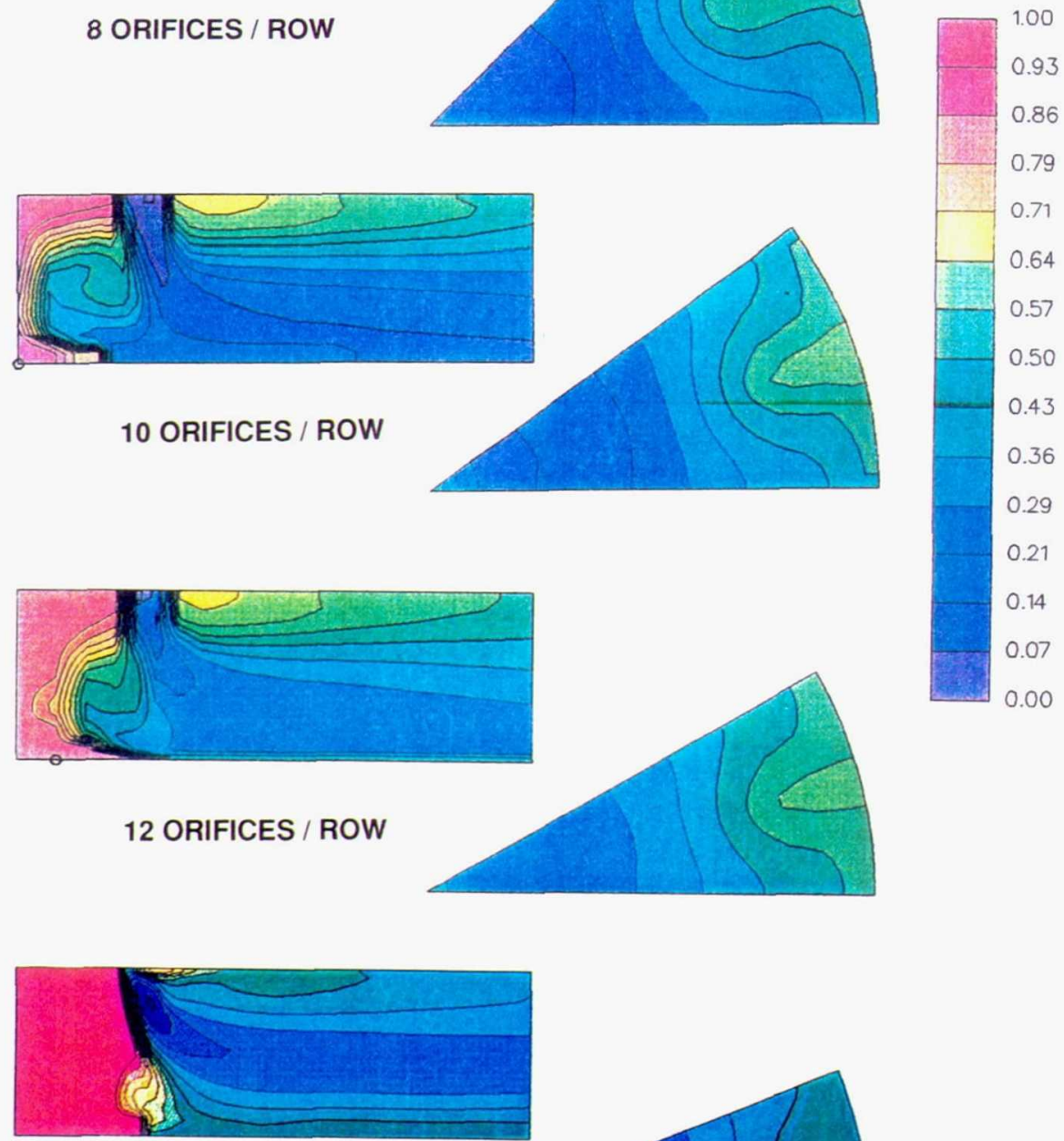

16 ORIFICES / ROW

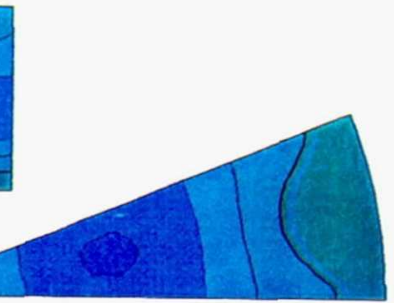

Figure 13. Effect of the number of square orifices on mixing for $\mathrm{J}=82.18, \mathrm{MR}=1.92, \mathrm{DR}=1.57$, $h_{\text {eq }}=0.343$. 
Page intentionally left blank 


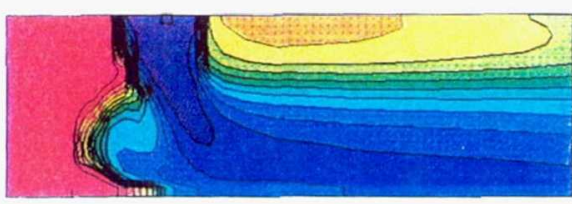

$\mathrm{L} / \mathrm{W}=1$

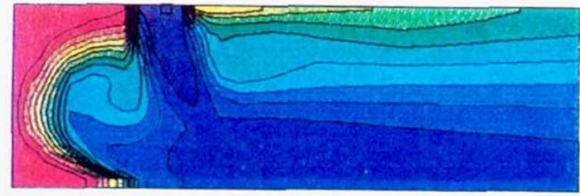

$\mathrm{L} / \mathrm{W}=2$

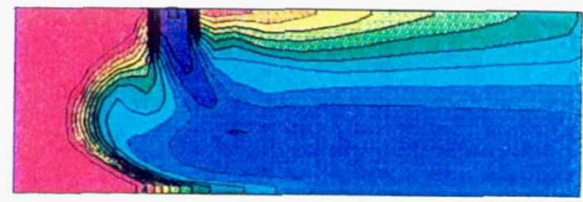

$\mathrm{L} / \mathrm{W}=4$

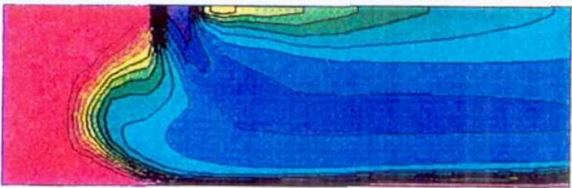

$\mathrm{L} / \mathrm{W}=6$

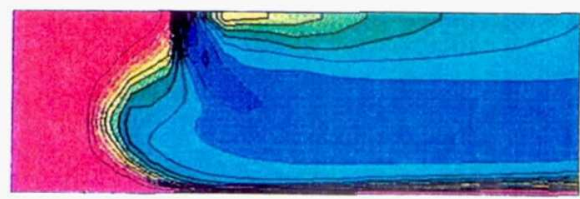

$\mathrm{L} / \mathrm{W}=8$

a. Axial-radial plane through orifice center
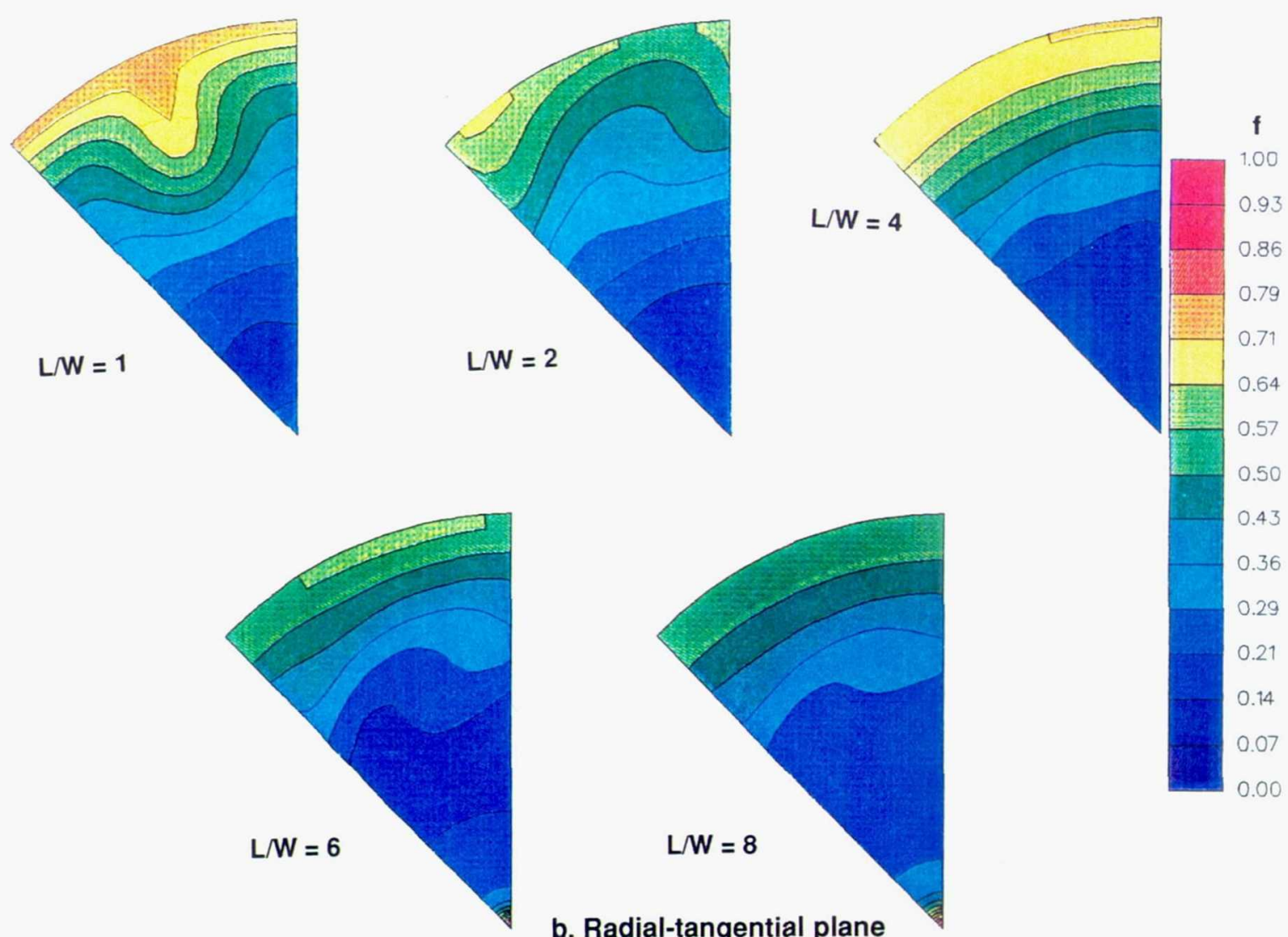

0.93

0.86

0.79

0.71

0.64

Figure 14. Effect of slot aspect ratio $(\mathrm{L} / \mathrm{W})$ on mixing for $\mathrm{J}=82.18, \mathrm{MR}=1.92, \mathrm{DR}=1.57$, slant angle $=$ $45 \mathrm{deg}, \mathrm{h}_{\mathrm{eq}}=0.343$. 
Page intentionally left blank 


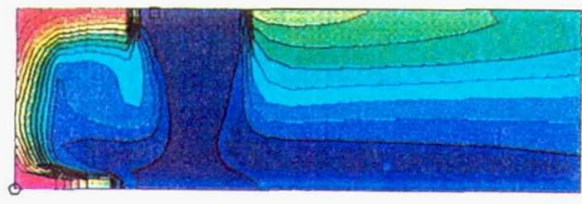

$\phi=0^{\circ}$

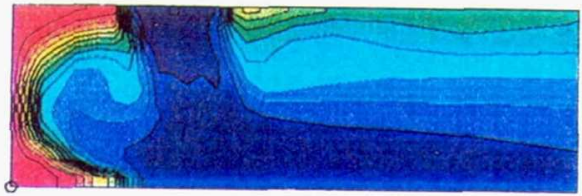

$\phi=15^{\circ}$

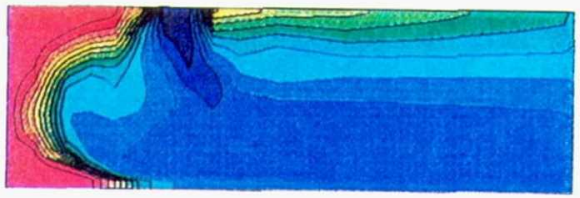

$\phi=30^{\circ}$

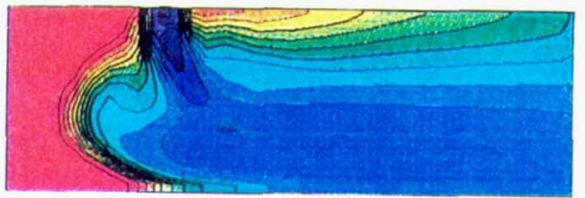

$\phi=45^{\circ}$
NORMALIZED ENTHALPY

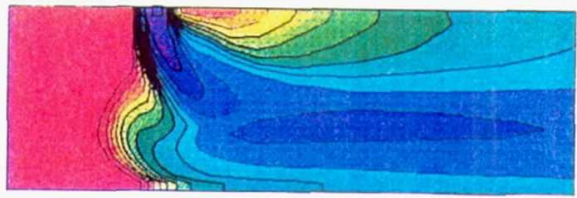

$\phi=60^{\circ}$

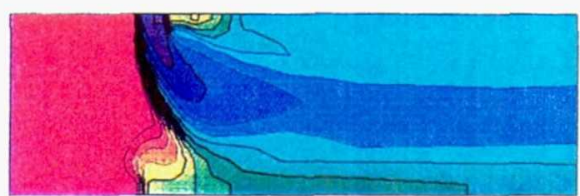

$\phi=75^{\circ}$

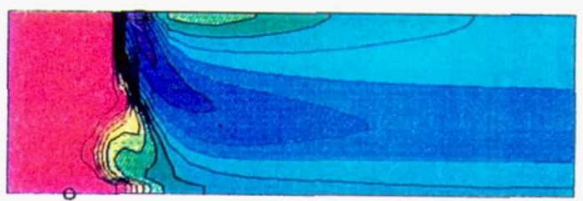

$\phi=90^{\circ}$

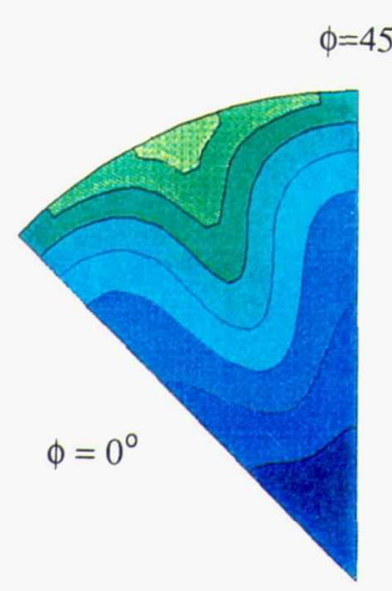

a. Axial-radial pıane through orifice center
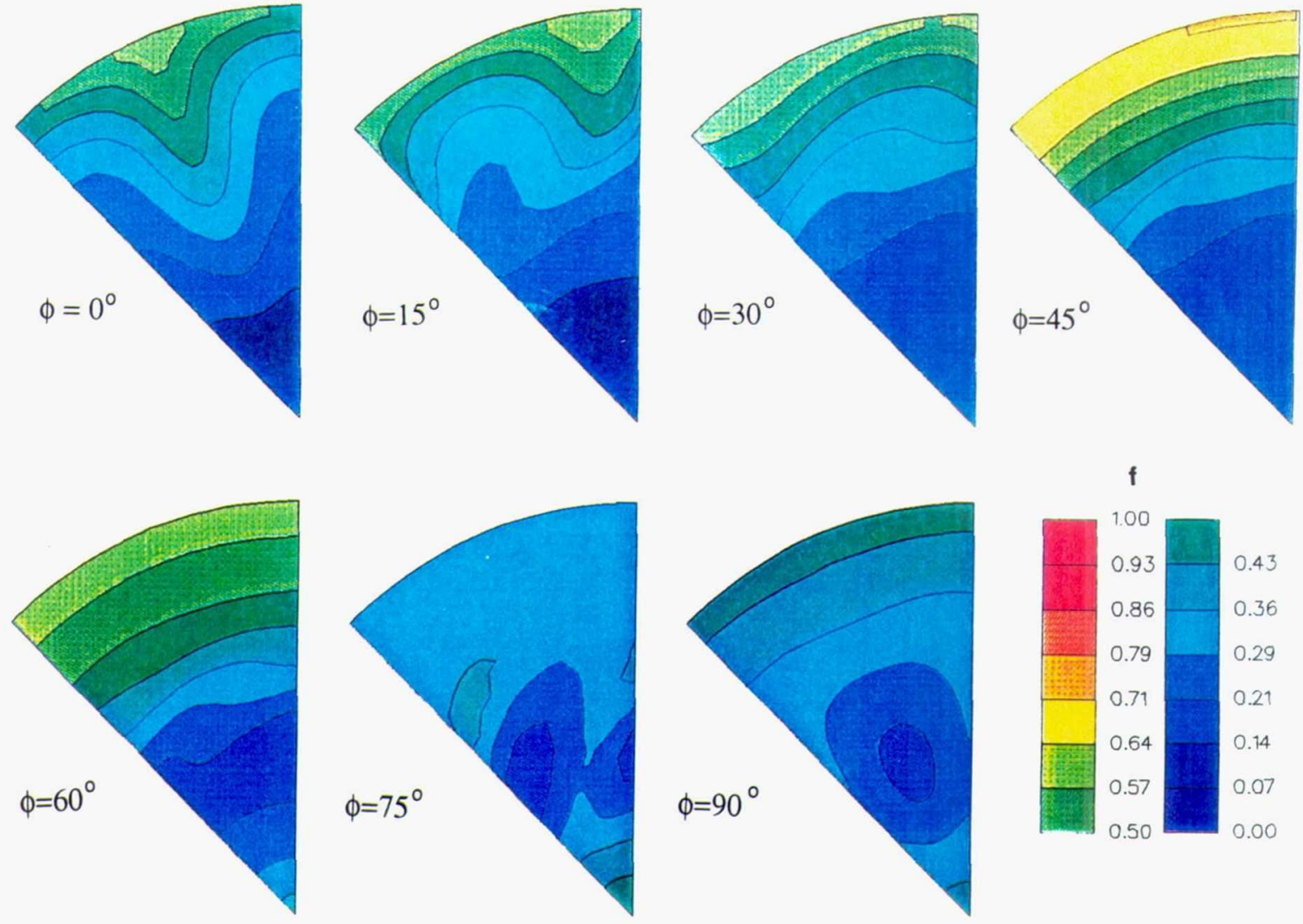

b. Radial-tangential plane

Figure 15. Effect of slot slant angle on mixing for $\mathrm{J}=82.18, \mathrm{MR}=1.92, \mathrm{DR}=1.57, \mathrm{~L} / \mathrm{W}=4, \mathrm{~h}$ eq $=0.343$. 
Page intentionally left blank 
a.
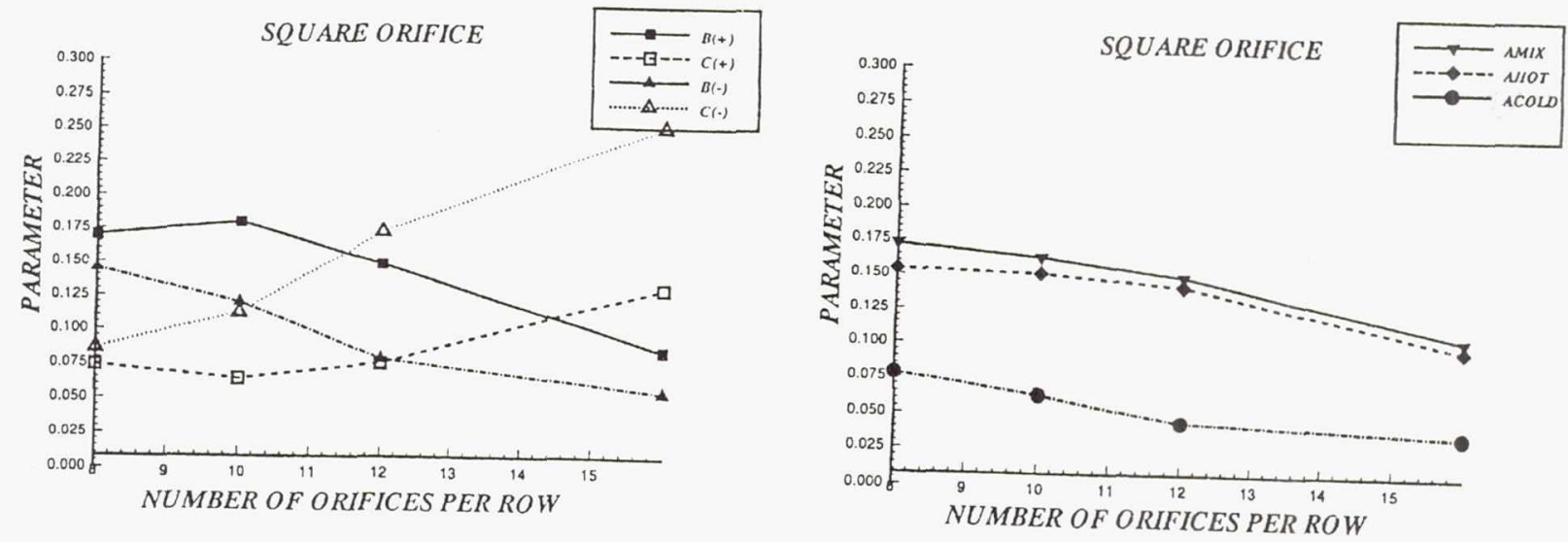

b.
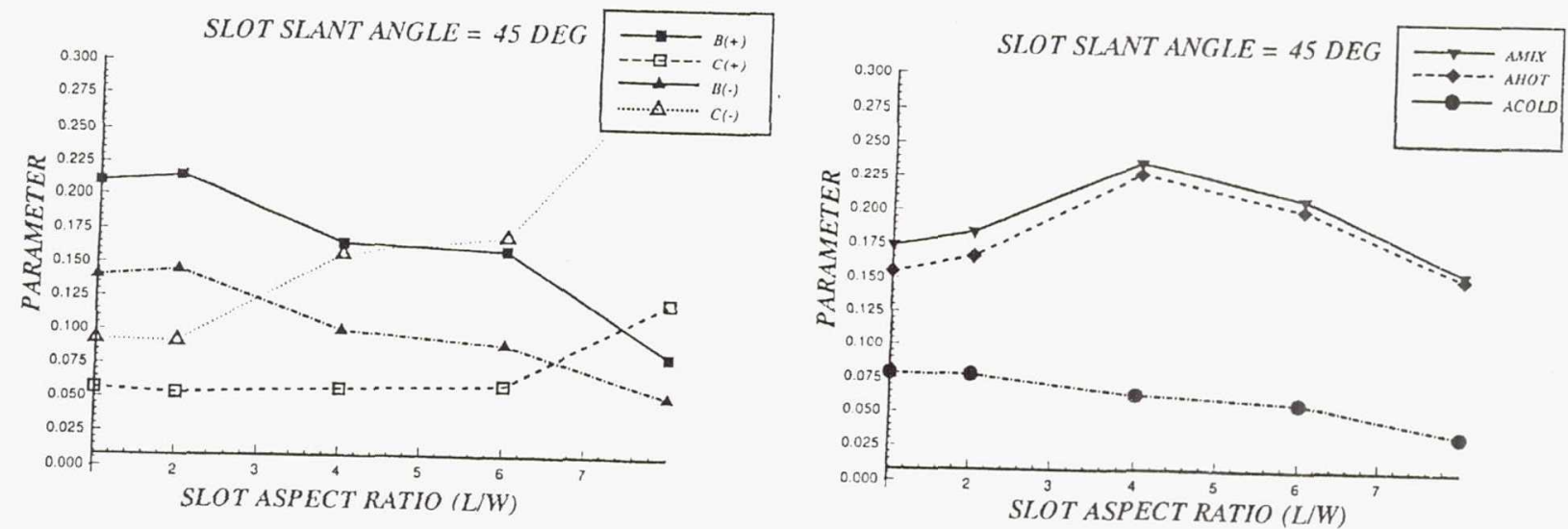

c.
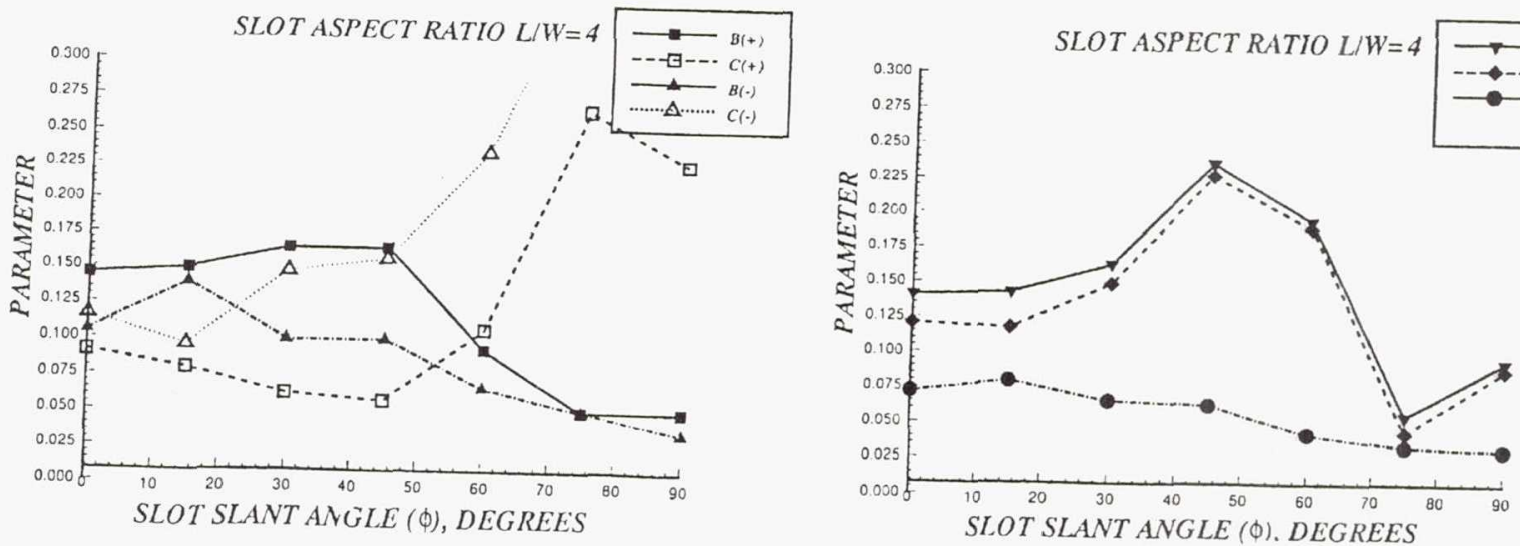

Figure 16. Statistical results of the parametric study at $J=82.18, M R=1.92$, and 1.57 . 
Public reporting burden for this collection of information is estimated to average 1 hour per response, including the time for reviewing instructions, searching existing data sources, gathering and maintaining the data needed, and completing and reviewing the collection of information. Send comments regarding this burden estimate or any other aspect of this collection of information, including suggestions for reducing this burden, to Washington Headquarters Services, Directorate for information Operations and Reports, 1215 Jefferson Davis Highway, Suite 1204, Arlington, VA 22202-4302, and to the Office of Management and Budget, Paperwork Reduction Project (0704-0188), Washington, DC 20503.

\begin{tabular}{|l|l|l|}
\hline 1. AGENCY USE ONLY (Leave blank) & $\begin{array}{r}\text { 2. REPORT DATE } \\
\text { July } 1992\end{array}$ & $\begin{array}{r}\text { 3. REPORT TYPE AND DATES COVERED } \\
\text { Technical Memorandum }\end{array}$ \\
\hline
\end{tabular}

\section{TITLE AND SUBTITLE}

5. FUNDING NUMBERS

A Parametric Numerical Study of Mixing in a Cylindrical Duct

\section{6. $A U T H O R(S)$}

V.L. Oechsle, H.C. Mongia, and J.D. Holdeman

WU-537-02-02

\section{PERFORMING ORGANIZATION NAME(S) AND ADDRESS(ES)}

National Aeronautics and Space Administration

Lewis Research Center

Cleveland, Ohio 44135-3191

8. PERFORMING ORGANIZATION REPORT NUMBER

E-7083

9. SPONSORING/MONITORING AGENCY NAMES(S) AND ADDRESS(ES)

10. SPONSORING/MONITORING AGENCY REPORT NUMBER

National Aeronautics and Space Administration

Washington, D.C. 20546-0001

NASA TM-105695

\section{SUPPLEMENTARY NOTES}

Prepared for the 28th Joint Propulsion Conference and Exhibit, cosponsored by the AIAA, SAE, ASME, and ASEE, Nashville, Tennessee, July 6-8, 1992. V.L. Oechsle and H.C. Mongia, Allison Gas Turbine Division, General Motor Corporation, Indianapolis, Indiana 46206, and J.D. Holdeman, NASA Lewis Research Center, Cleveland, Ohio 44135. Responsible person, J.D. Holdeman, (216) 433-5846.

12a. DISTRIBUTION/AVAILABILITY STATEMENT

12b. DISTRIBUTION CODE

Unclassified - Unlimited

Subject Category 07

13. ABSTRACT (Maximum 200 words)

This paper describes the interaction of some of the important parameters affecting the mixing process in a quick mixing region of a rich burn/quick mix/lean burn (RQL) combustor. The performance of the quick mixing region is significantly affected by the geometric designs of both the mixing domain and the jet inlet orifices. In this paper, several of the important geometric parameters and operating conditions affecting the mixing process were analytically studied. Parameters such as jet-to-mainstream momentum flux ratio (J), mass flow ratio (MR), orifice geometry, orifice orientation, and number of orifices/row (equally spaced) around the circumferential direction have been analyzed. Three different sets of orifice shapes were investigated: (1) square, (2) elongated slots, and (3) equilateral triangles. Based on the analytical results, the best mixing configuration depends significantly on the penetration depth of the jet to prevent the hot mainstream flow from being entrained behind the orifice. The structure in a circular mixing section is highly weighted toward the outer wall and any mixing structure affecting this area significantly affects the overall results. The increase in the number of orifices per row increases the mixing performance. Strong swirl in the quick mixing region appears to have an adverse effect on mixing at higher J conditions. Higher slot slant angles and aspect ratios are generally the best mixing configurations at higher momentum-flux ratio $(\mathrm{J})$ conditions. However, the square and triangular shaped orifices were more effective mixing configurations at lower J conditions.

\section{SUBJECT TERMS}

Dilution; Jet mixing flow; Gas turbine; Combustion chamber; Emissions

\begin{tabular}{|c|c|}
\hline $\begin{array}{c}\text { 17. SECURITY CLASSIFICATION } \\
\text { OF REPORT } \\
\text { Unclassified }\end{array}$ & $\begin{array}{c}\text { 18. SECURITY CLASSIFICATION } \\
\text { OF THIS PAGE } \\
\text { Unclassified }\end{array}$ \\
\hline
\end{tabular}
19. SECURITY CLASSIFICATION OF ABSTRACT Unclassified

